\title{
HYBRIDITY SELECTION IN CAMPANULA
}

\author{
C. D. DARLINGTON and L. F. LA COUR
}

John Innes Horticultural Institution, Bayfordbury, Hertford, Herts.

Received 25.viii.49

\section{CONTENTS}

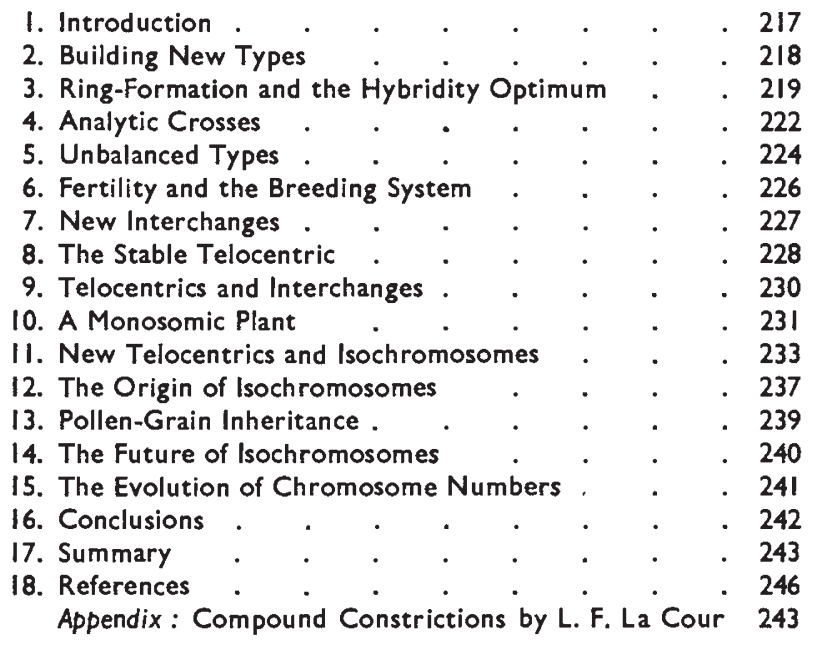

\section{INTRODUCTION}

IN our first account of ring formation in Campanula persicifolia (Gairdner and Darlington, I93I) we showed how mechanical rules could be applied for the construction of plants with large rings at meiosis by the combination of interchanged chromosomes found in wild races. In our second account (Darlington and Gairdner, 1937) we showed how large rings were maintained by the elimination of homozygotes but broke down more frequently than those stabilised by natural selection in Oenothera, owing to the occurrence of crossing-over between interstitial segments in opposite complexes. We also showed the high degree of structural hybridity in regard to inversions which was correlated with interchange hybridity in a cross-fertilising species. Our present object is to make use of the interchanges and other breakages as markers in determining how hybridity is maintained by selection in the species, in other words how the breeding system works. In this programme the origin, maintenance and breakdown of telocentric chromosomes plays a part.

We are indebted to Dr Margaret Upcott for the crossings, scorings, drawings, photographs and fertility records from 1937 to 1939 . 
The earlier preparations of pollen mother-cells were aceto-carmine and Feulgen smears, the later acetic lacmoid. Feulgen alone was suitable for the pollen-grain mitosis owing to the thickness of the walls.

Symbols. - The fraction of the circle in black used in the tables represents the fraction of the 16 chromosomes in the ring or rings. Pairs of single lines outside the circle represent pairs of telocentrics, opposite pairs represent telocentric bivalents; pairs of joined lines, isochromosomes; attachment to rings or to free chromosomes is indicated by position. $t$, telocentric ; iso, isochromosomes. $B$, Basic type, the common original type found generally in Europe in the absence of interchange. $R$, reciprocal crosses.

\section{BUILDING NEW TYPES}

In the first place it is necessary to record the continuation of the work of building new types of structural heterozygotes by crossing individuals carrying different interchanges. The products of such

TABLE $I$

Synopsis of families since 1937

Recombination progenies from crossing dissimilar parents $R$ : include reciprocal crosses

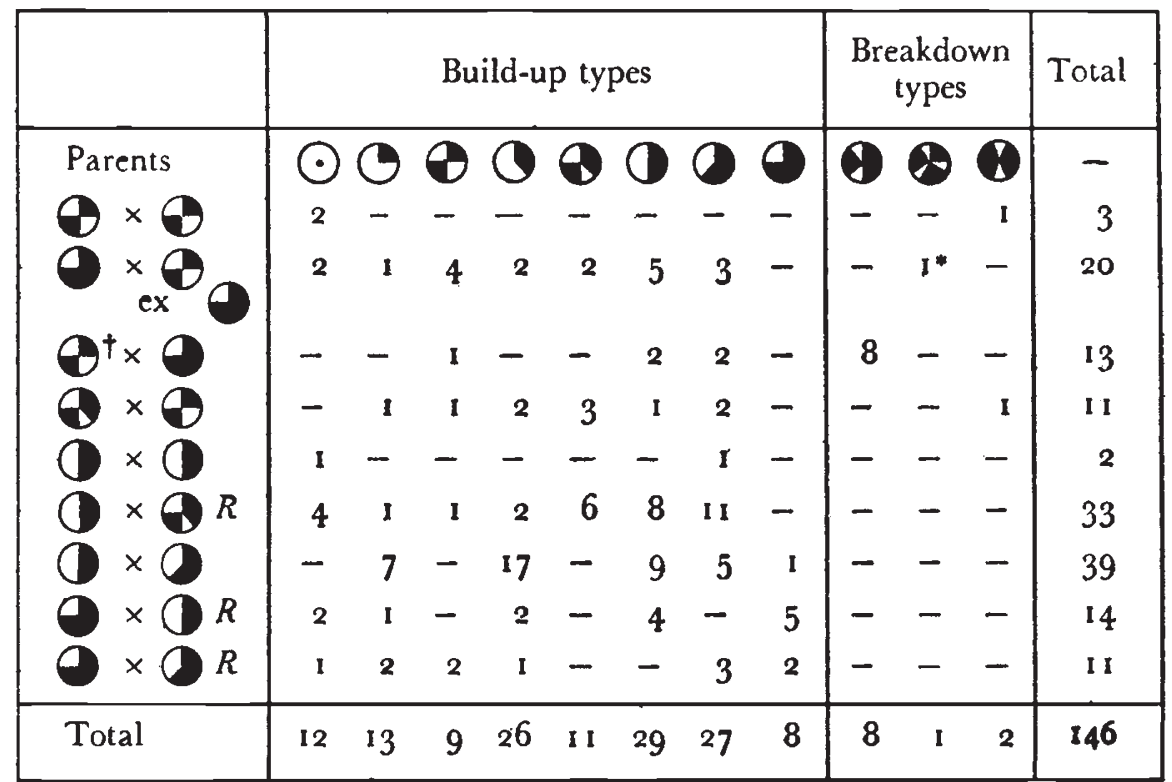

* Due to new interchange in one parent

$\dagger$ Russian

synthetic crosses consist of old types, and new ones with larger rings ; but they also include what we may call breakdown types in which the rings formed represent a partial disintegration of a ring-of-twelve, i.e. $6+6,8+4$, and $4+4+4$ (Table $\mathrm{I}$ ). 


\section{RING-FORMATION AND THE HYBRIDITY OPTIMUM}

The results of selfing and inter-crossing similar ring types of plant are, apart from unbalanced forms, of three kinds :-

(i) Structural heterozygotes with the parental type of ring.

(ii) Structural homozygotes with eight bivalents : they are homozygous for the structural arrangements of one of the two balanced complexes produced by segregation in a ring.

(iii) Intermediates with smaller or fewer rings: these last are the result, either of crossing-over or of non-disjunction within the ring of the kind which gives half-mutants in Oenothera, or again of homozygosis for one ring where the parents had two.

In order to interpret our results we have to consider what differences are to be expected between the structural heterozygotes and homozygotes in selfs and also in crosses. For this purpose the chromosomes

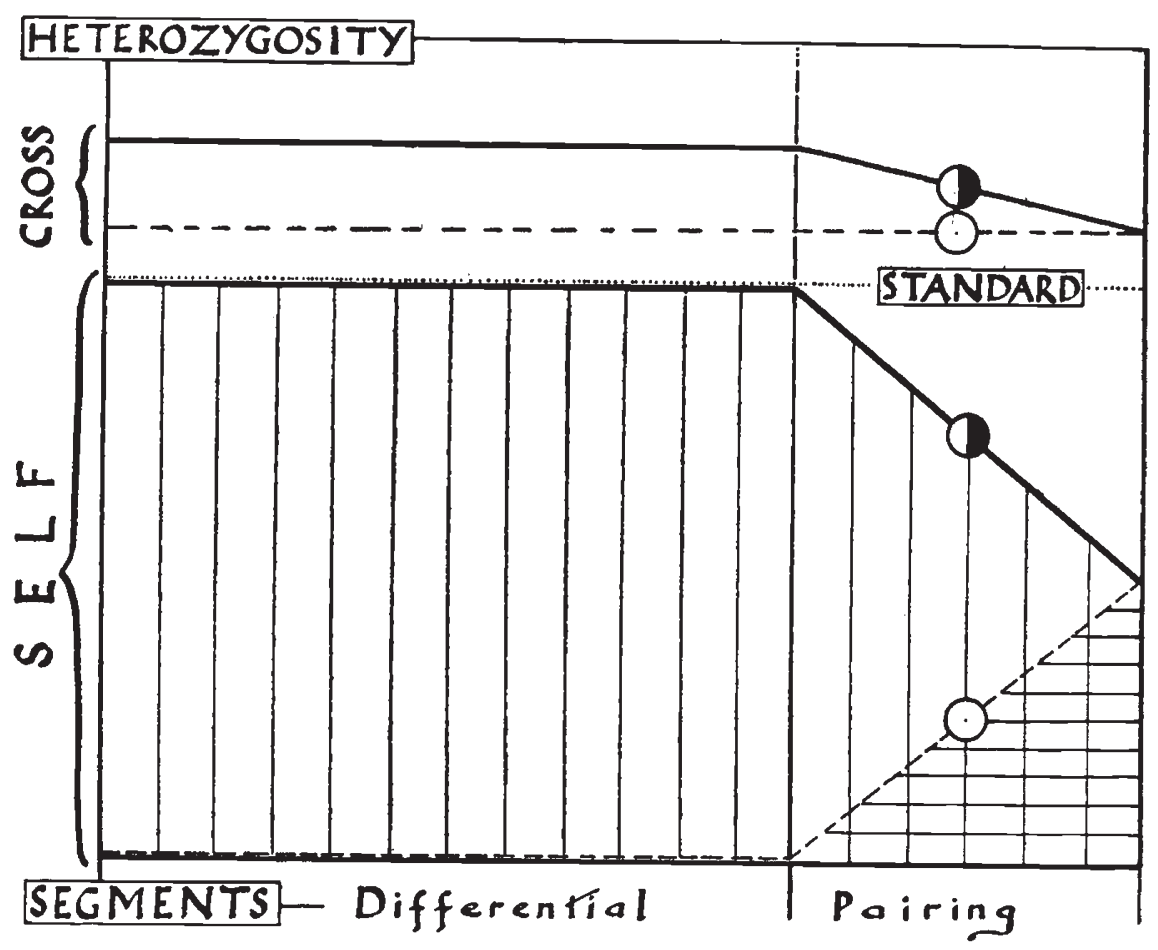

FIG. 1.-Graph showing comparative heterozygosity of selfed and crossed plants in respect of the pairing and differential segments of chromosomes derived from a ring (e.g. a ring-of-eight), the ring parent being the standard.

in ring parents consist of two parts, the differential segments which cannot cross over with their homologues, and the pairing segments which can and do cross over. So far as any particular plant is concerned what matters is the position of the chiasmata in its parental mother-cells. 
But in a sample of plants the pairing segments will show a gradient from no crossing-over next to the differential segments to 50 per cent. crossing-over at the ends.

Now take the progeny from selfing a ring plant, structurally homozygous (non-ring) and heterozygous (ring). The non-rings will be genically homozygous for their differential segments and have a

TABLE 2

Synopsis of families since 1937 D. and G. table III

Maintenance progenies, from similar parents, 150 seedlings

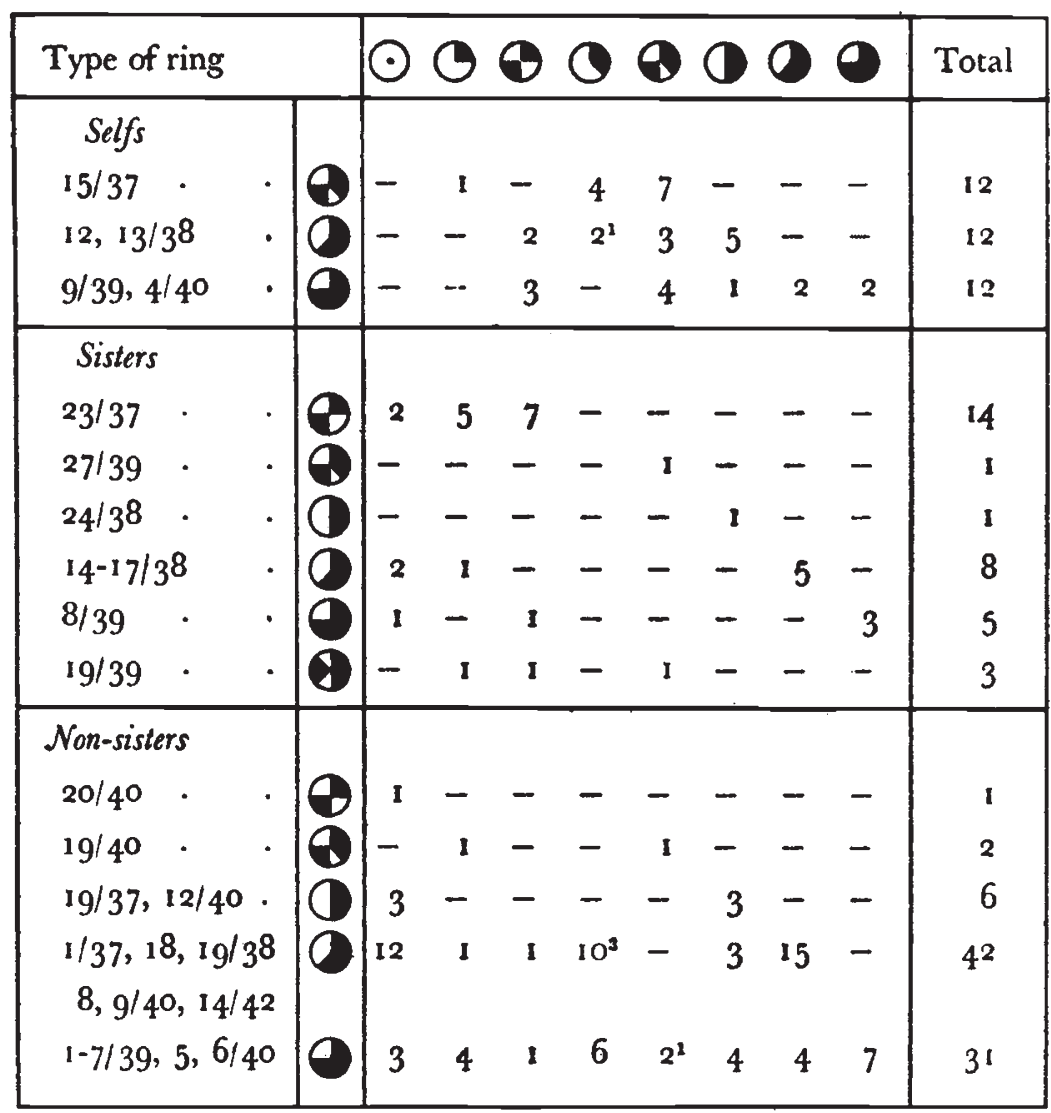

Note.-Index numbers on progeny show the numbers that were trisomic and therefore of non-disjunctional origin.

genic heterozygosity rising in a gradient in the pairing segments towards half the parental degree at the ends. The rings will be genically as heterozygous as the parent was for the differential segments and have a genic heterozygosity diminishing in the pairing segments towards half the parental amount at the ends. In other words rings and non-rings will be sharply differentiated in genic as well as in structural heterozygosity. 
TABLE 3

Progenies of similar parents according to their relationships

(total data before and since 1937)

(i) Single RINGs (lower rings are due to breakdown by crossing-over or non-disjunction)

(ii) DoUble RINGS (single rings are due to recombination)

\begin{tabular}{|c|c|c|c|c|}
\hline \multirow[b]{2}{*}{ Parents } & \multicolumn{4}{|c|}{ Offspring } \\
\hline & & $\begin{array}{l}\text { Lower ring } \\
\text { or } \\
\text { single ring }\end{array}$ & Parent type & Total \\
\hline (i) SingLe RINGS & $\left.\begin{array}{l}- \\
- \\
- \\
-\end{array}\right\} \begin{array}{c}0 \\
0.0 \%\end{array}$ & $\left.\begin{array}{c}4 \\
1 \\
12 \\
10\end{array}\right\} \begin{array}{c}27 \\
77 \cdot 1 \%\end{array}$ & $\left.\begin{array}{c|c}1 \\
- \\
2\end{array}\right\} 22 \cdot 9 \%$ & 35 \\
\hline Sister & $\left.\begin{array}{c}- \\
10 \\
2 \\
2\end{array}\right\} \begin{array}{c}14 \\
28 \cdot 0 \%\end{array}$ & $\left.\begin{array}{c}- \\
2 \\
1 \\
1\end{array}\right\} \begin{array}{c}4 \\
8.0 \%\end{array}$ & $\left.\begin{array}{c}7 \\
17 \\
5 \\
3\end{array}\right\} \begin{array}{r}3^{2} \\
64 \cdot 0 \%\end{array}$ & 50 \\
\hline Non-sister & $\left.\begin{array}{r}3 \\
12 \\
3\end{array}\right\} \begin{array}{c}18 \\
22 \cdot 7 \%\end{array}$ & $\left.\begin{array}{l}- \\
15 \\
20\end{array}\right\} \begin{array}{c}35 \\
44 \cdot 4 \%\end{array}$ & $\left.\begin{array}{r}3 \\
16 \\
7\end{array}\right\} \begin{array}{c}26 \\
32 \cdot 9 \%\end{array}$ & 79 \\
\hline Total & 32 & 66 & 66 & 164 \\
\hline $\begin{array}{l}\text { (ii) Double RINGs } \\
\text { Self }\end{array}$ & $\begin{array}{l}- \\
-\end{array}$ & $\begin{array}{l}\text { I } \\
5\end{array}$ & $\begin{array}{l}2 \\
7\end{array}$ & $\begin{array}{r}3 \\
12\end{array}$ \\
\hline Sisters & $\begin{array}{l}2 \\
- \\
-\end{array}$ & $\begin{array}{l}5 \\
- \\
3\end{array}$ & $\begin{array}{r}7 \\
1 \\
-\end{array}$ & $\begin{array}{r}14 \\
1 \\
3\end{array}$ \\
\hline Non-sisters $\Theta$ & $\begin{array}{r}I \\
-\end{array}$ & - & - & $\begin{array}{l}1 \\
2\end{array}$ \\
\hline Total $(1: 2: 1)$ & 3 & 15 & 18 & 36 \\
\hline
\end{tabular}


The progeny from crossing with plants having similar rings but dissimilar ancestry will not be distinguished in anything like the same degree. The structural homozygotes can be genically highly heterozygous and the structural heterozygotes need be little more so. Again, in the pairing segments, what difference there is will decrease towards the ends. The points of interchanges, as indeed of inversions, are thus markers of ancestry and differentiation. But since the interchanges (in Campanula) can be taken to pieces and put together again, they have to be considered more than are inversions, together with the known relationships of chromosomes and plants (fig. I, p. 219).

If there is a differential elimination of genic homozygotes in mixed progenies the proportion of structural homozygotes and heterozygotes should therefore differ with the relations of the parents. Structural homozygotes should be fewest (and rings commonest) in the selfed progeny, more frequent in sister and non-sister progeny. This is in fact the case for both single and double rings (tables 2 and 3 ). The use of the interchanges as markers thus enables us to prove the existence of a hybridity optimum which is favoured by selection. The non-rings are eliminated in selfs since they depart in character from the naturally selected products of the breeding habit of the species. But they are not eliminated in crosses since here they conform in character with those naturally selected products.

It will be noted, on the other hand, that low rings from high rings (table 2(i), due to crossing-over) are favoured in selfs and non-sister crosses but that single rings from double rings (table 2 (ii), due to recombination of the pre-existing types) are not so favoured. This would indicate that certain low rings were favoured in certain crosses, not because they gave the maximum gene-hybridity, but because they constitute appropriately balanced combinations. It is a question of external balance being more important than internal balance (to use Mather's, 1942, distinction) in particular combinations. Catcheside (1936) has arrived at the same conclusion in Oenothera by showing that the addition of different extra chromosomes will render a particular lethal diploid combination viable.

\section{ANALYTIC CROSSES}

In building multiple from single interchange rings the interchanges are not likely to be all on the same side of the ring. In our high rings both sides of the ring and both gametic types should therefore contain interchanges with respect to our original basic type. When they are crossed with basic types all the progeny will therefore be expected to show rings, chiefly rings-of-four. This is borne out by the results of our analytic crosses. Apart from one presumed mistake, all the progeny have rings, most of them two rings-of-four (table 4).

The non-ring or structurally homozygous progeny from selfing high rings must therefore be interchange homozygotes. We might expect 
that those from rings-of-eight, -ten and -twelve would usually give two rings-of-four when crossed with the basic type. In fact in all five test families they uniformly did so (table 5). It seems likely therefore that this combination of interchanges is the only one in our high-ring stocks which is viable as a homozygote. One apparent exception to this rule was manifestly spurious and due to a new interchange (section 8).

TABLE 4

Synopsis of families since 1937

Analytic crosses, i.e. between high rings and basic tomozygotes ( 1 i 2 seedlings)

\begin{tabular}{|c|c|c|c|c|c|c|c|c|}
\hline Families & $\begin{array}{l}\text { Ring } \\
\text { parent }\end{array}$ & $\odot$ & $\mathcal{O}$ & $\theta$ & 7 & $\theta$ & 2 & Total \\
\hline$(1937)$ & & - & 14 & - & - & - & - & 14 \\
\hline (1937 et seq.) & & - & 6 & 15 & - & - & - & 21 \\
\hline $\begin{array}{l}20,21 / 3^{8} \text { and } \\
48 / 39 ; 10 / 4^{2}\end{array}$ & & - & $3^{*}$ & $20 \dagger$ & - & 2 & - & 25 \\
\hline $7^{-10 / 3^{8}}$ & & - & - & $3^{2}$ & - & 12 & $2 \dot{T}$ & 46 \\
\hline $21 / 48 ; 9 / 4^{2}$ & & $(\mathrm{I}) \S$ & 2 & 2 & I & I & - & 6 \\
\hline Total & & - & 25 & 69 & I & 15 & 2 & 112 \\
\hline
\end{tabular}

TABLE 5

Synopsis of families since 1937

Test crosses between basic (B) and extracted homozygotes

\begin{tabular}{|c|c|c|}
\hline Parents & No. of families & Progeny \\
\hline$\odot$ ex $\bigcirc \times \odot$ B & 2 & $3 \Theta$ \\
$\odot$ B $\times \odot$ ex $\odot$ & 2 & $5 \Theta$ \\
$\odot$ ex $\odot \times \odot$ B & 1 & $2 \Theta$ \\
\hline
\end{tabular}

Thus single interchanges and certain combinations of interchanges are lethal and, therefore, capable in themselves of maintaining the ring in Campanula, making it breed true by a balanced lethal system in nature. Certain combinations of interchanges, however, are not lethal in the homozygous condition. One interchange, or at least one interchanged chromosome, sometimes compensates for the effects of another. This point was also proved by the segregation of non-basic homozygotes from the Russian stocks dealt with later. 


\section{UNBALANCED TYPES}

Non-disjunction increases in frequency with the size of the ring. It was numerically unequal in 29 per cent. of pollen mother-cells with a ring-of-eight, in 50 per cent. with a ring-of-ten. Trisomics, therefore, have appeared in the progeny of plants with rings-of-eight, -ten or -twelve but not with smaller rings. The extra chromosome which is sometimes lost somatically, can be transmitted through the pollen as well as through the eggs (table 6). Even when the trisomic is used as the mother, however, the trisomic progeny is less frequent than the disomic and is evidently less viable (table 7).

TABLE 6

Origin of trisomics

\begin{tabular}{|c|c|c|c|}
\hline Female parent & Male parent & No. of progeny & Trisomics \\
\hline \multirow[t]{2}{*}{$(1$} & 0 & 35 & 2 \\
\hline & & 7 & I \\
\hline \multirow[t]{2}{*}{0} & 0 & 33 & 3 \\
\hline & 0 & 7 & I \\
\hline$\odot$ & 0 & 12 & I \\
\hline Total & & 97 & 8 \\
\hline
\end{tabular}

Note.-Since no trisomics have been found in the progeny of non-rings or even lower rings than eight, the extra chromosome from a basic $\times(12)+2(2)$ must be derived from a ring of the father. It is attached to one of the two rings-of-four in the offspring.

TABLE 7

Progenies showing partial elimination of the extra chromosome of a trisomic in transmission on the female side

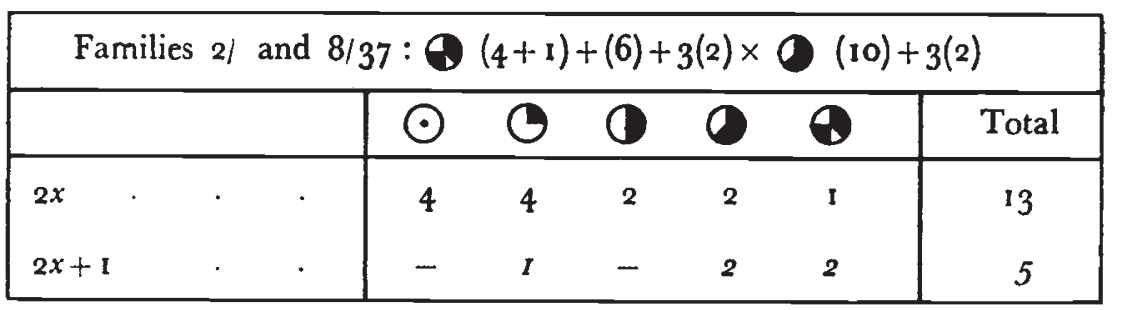

The trisomic plants have configurations at meiosis of the types classified by Catcheside (1936) according to the kind of non-disjunction by which they arise (fig. 2). They have in addition aberrant configurations, some due to the pairing of the reduplicated distal segments previously described, and some presumably due to the formation of ring bivalents with chiasmata proximal to a small terminal interchanged segment (fig. 3). In our progeny records the 


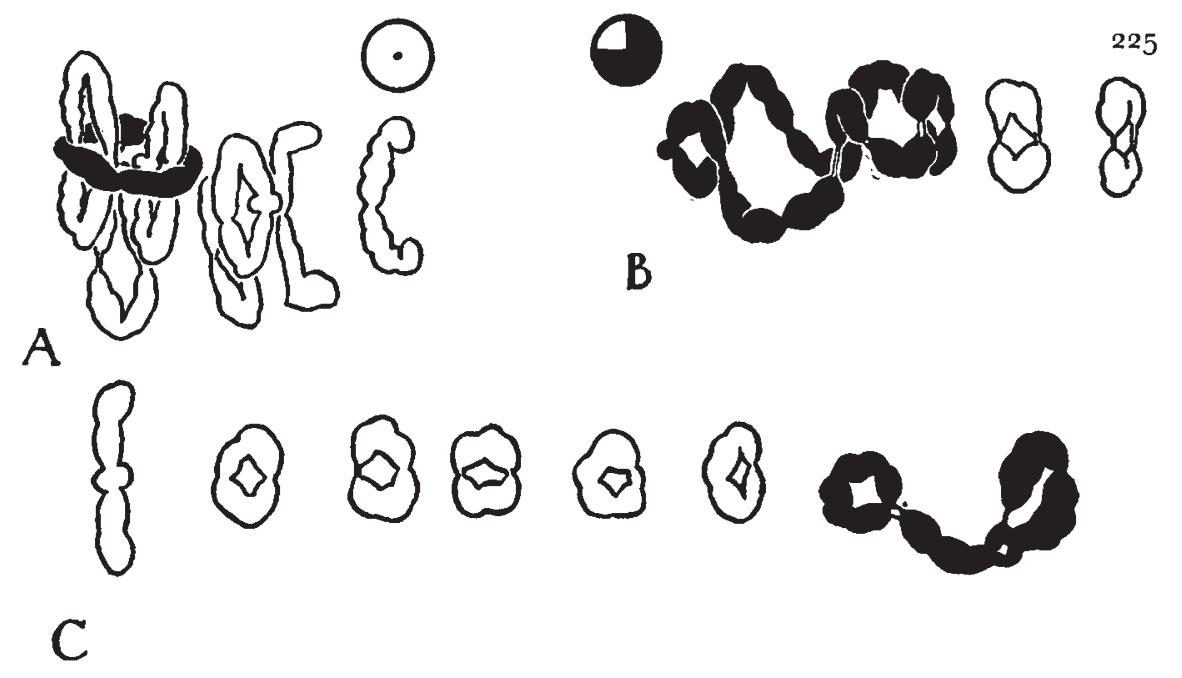

FIG. 2.-First metaphase of meiosis in the pollen mother-cells of Campanula persicifolia.

A Interlocking in Russian plant (Valdai) with 8 bivalents $\left(49^{22} / 37\right)$.

B. Ring-of-twelve in $6^{8} / 3^{8}$.

C. Trisomic plant with extra chromosome joining 2 bivalents $\left(2^{13} / 37\right)$. Figs. 2 to II magnified $\times 2700$. The symbols in the figures illustrate those used in the tables.

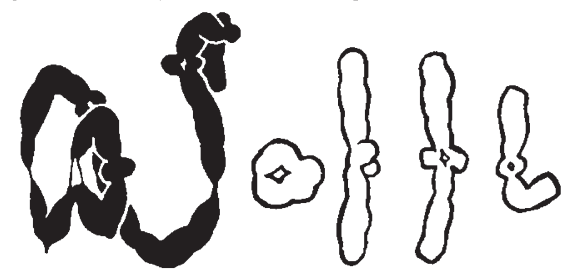

A
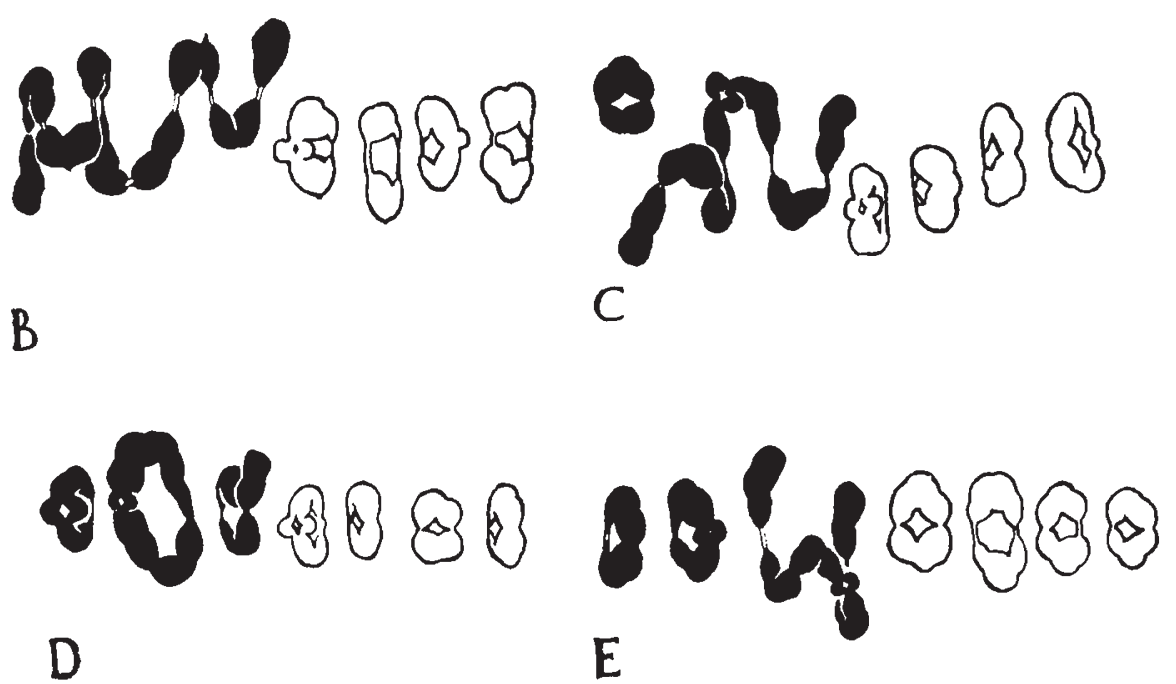

FIG. 3.-Various configurations in a trisomic plant with rings-of-two and -four joined by a chain-of-three. The black bivalents in $\mathrm{C}, \mathrm{D}$ and $\mathrm{E}$ are derived from the chain-of-nine in $\mathrm{B}$. One of these in $\mathrm{D}$ and $\mathrm{E}$ is not a true bivalent; it has an interchanged end distal to the interstitial chiasma. 
trisomics are scored according to the total number of interchanges shown by the maximum association.

Two tetraploids arose in crosses, one between 2(4) and (6) $+(4)$, the other between (10) and $(6)+(4)$. Probably they resulted from gametic non-reduction on both sides since multiple and high rings hinder a regular anaphase. From the second of these, crossed with a basic diploid, one capsule gave 200 seeds but only one seedling, a triploid. This, crossed as a female with a diploid, gave progeny with 19 and 20 chromosomes, in form and habit not distinctly different from a sister with 16 chromosomes but smaller.

\section{FERTILITY AND THE BREEDING SYSTEM}

The previous account showed the dependence of seed fertility on the female parent. The greater the number of interchanges involved in its ring the lower its fertility. The present extended data show more (table 8). Now it is clear that the male parent, at least with

TABLE 8

Fertility summary (including table 7 of D. and G. 1937)

Percentages of potential maximum of 600 seedlings per capsule produced in various crosses showing correlation with the number of interchanges in the female, but not in the male, parent.

\begin{tabular}{|c|c|c|c|c|c|c|c|c|c|}
\hline \multirow{2}{*}{$\begin{array}{c}\begin{array}{c}\text { Number of } \\
\text { interchanges }\end{array} \\
\end{array}$} & o & 1 & 2 & 2 & 3 & 3 & 4 & 5 & \multirow{2}{*}{ Average } \\
\hline & $\odot$ & 0 & $\theta$ & 0 & $\theta$ & 0 & 0 & 0 & \\
\hline$\odot$ & 30 & 24 & - & 27 & - & 21 & 20 & 21 & $24 \cdot 0 \%$ \\
\hline 0 & 27 & II & - & - & - & - & - & - & $19 \cdot 0 \%$ \\
\hline$\theta$ & - & - & 9 & - & - & $\mathrm{I} \cdot 5$ & 5 & - & $5.5 \%$ \\
\hline 0 & 12 & - & - & 14 & - & - & - & - & $13.0 \%$ \\
\hline$\theta$ & - & - & - & - & 13 & - & - & - & $13.0 \%$ \\
\hline 0 & 3.5 & - & - & - & $I \cdot 3$ & $2 \cdot 3$ & 4.0 & $3 \cdot 3$ & $2 \cdot 9 \%$ \\
\hline 0 & 6.0 & - & - & - & $\mathrm{I} \cdot 5$ & - & 20 & $2 \cdot 0$ & $2 \cdot 9 \%$ \\
\hline 0 & $2 \cdot 5$ & - & - & - & $\mathrm{I} \cdot 6$ & $1 \cdot 0$ & $1 \cdot 5$ & 0.5 & $I \cdot 4 \%$ \\
\hline
\end{tabular}

artificial and therefore excessive pollination, has little or no influence on seed fertility. Thus pollen which can fertilise the egg is equally able in all classes to produce viable embryos. And unbalance, produced by excess or deficiency of whole chromosomes, is eliminated largely or entirely in the haploid stages of pollen and embryo-sac.

The irregularity and infertility of large rings produced experimentally in Campanula may be contrasted with the fertility of the large natural rings of Oenothera, Rhoeo, and Hypericum. In these regularity must have been achieved as a result of a slow process of 
selection during the development of the ring. This development has been traced in parallel in several sections of Oenothera by Cleland (I944) who finds that it is accompanied by a change of habit from cross- to self-fertilisation. We can now see from the differential elimination of homozygotes in Campanula, described in section 3 , that the transition is bound to favour the selective survival of ring-forming progeny and hence determine the evolutionary sequence which has been inferred in Oenothera.

The conclusion to be derived from the differential elimination may also be expressed in general terms to cover the evolutionary consequences where ring-formation is not brought into play. We may say that wherever there is a rise or fall in the size of a mating group the degree of heterozygosity of the population will not rise or fall correspondingly without a time lag. The breeding system is self-buffered against change.

\section{NEW INTERCHANGES}

Additional interchanges, enabling us to increase the ring still further, have been found in Russia. Rings-of-four occur in seed from three new localities (table 9a). Crosses again showed that all the

TABLE $9 a$

Origin of new interchanges and telocentric fragments. Seed collected 1937 : 72 seedlings

\begin{tabular}{|c|c|c|c|c|c|}
\hline Collector & I.ocality & Symbol & \multicolumn{3}{|c|}{ Samples } \\
\hline $\begin{array}{l}\text { H. G. Tedd (through } \\
\text { W. B. Turrill) }\end{array}$ & Xanthi (Thrace) & - & 14 & 0 & 0 \\
\hline H. N. Barber & Stolzenfels (Coblenz) & Stz & 10 & I & $\mathbf{0}$ \\
\hline , & Heidelberg & - & 3 & 0 & 0 \\
\hline Pojarkova & $\begin{array}{l}\text { Oranienbaum, near } \\
\text { Leningrad }\end{array}$ & Or & 17 & 5 & o \\
\hline Savicz & Valdai Hills & $\mathrm{Val}+$ & 20 & 1 & I \\
\hline
\end{tabular}

* Proved to be basic by crossing with basic types and inter se.

$\dagger$ One of each of the three types had a new character " dark pollen."

rings depended on combinations of single interchanges with the basic type : it was common to western and eastern Europe. They also showed that two of the Oranienbaum interchanges were different and both were different from the Valdai interchanges (table $9 b$ ). It seems that on its eastern frontier the species becomes more tenacious of its chromosome variability. This variability is also shown in a new way now to be described. 
TABLE $9^{b}$

Relationships of new interchanges (29 seedlings)

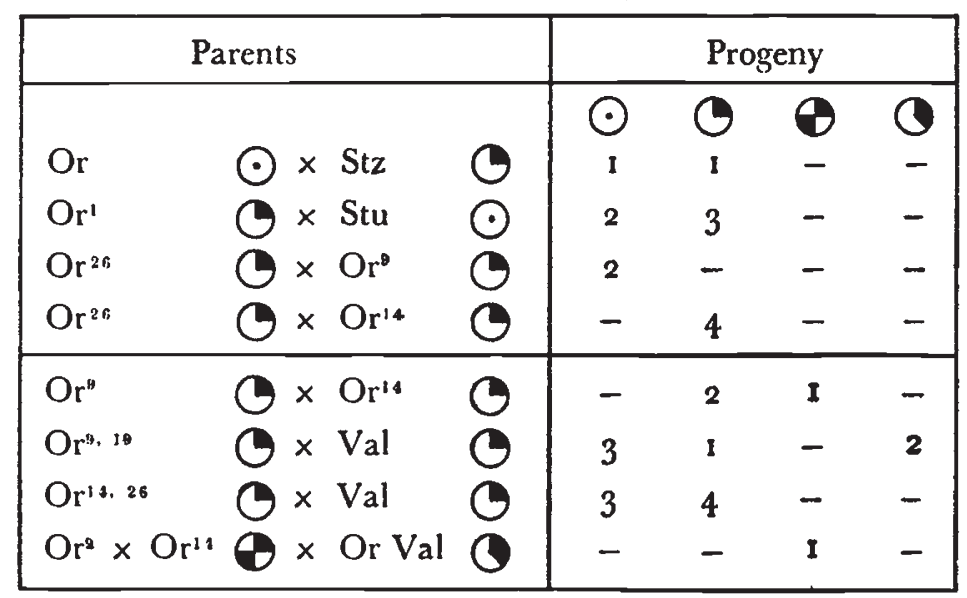

\section{THE STABLE TELOCENTRIC}

One of the Valdai plants had seven-ring bivalents and a chainof-three (fig. 4A). Two small telocentric chromosomes were united with the two arms of an ordinary chromosome. Each was equal in

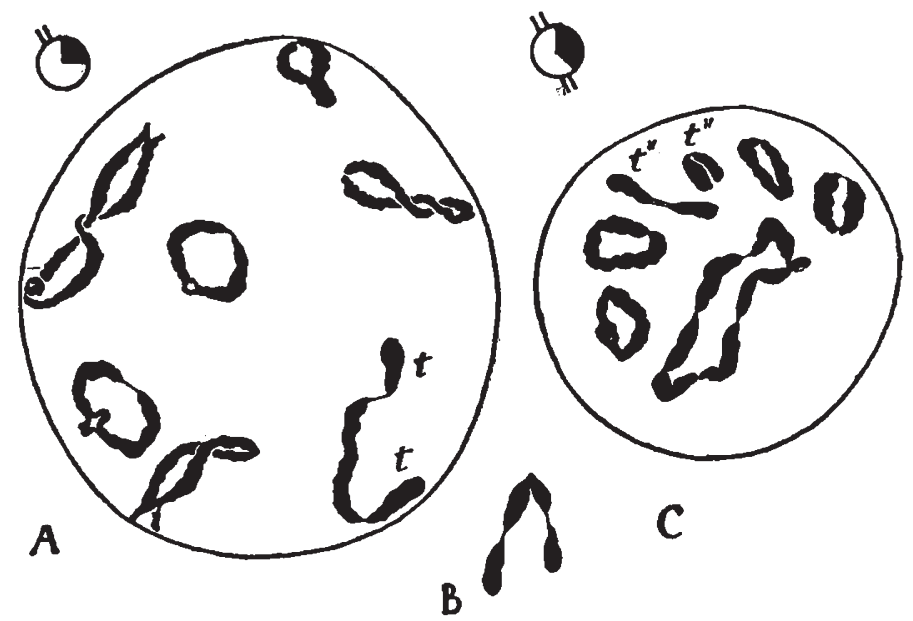

Fig. 4

A. Heterozygous telocentric triad with ring-of-four at late diplotene.

B. Telocentric triad at metaphase : each telocentric equal to the arm it is paired with.

C. Homozygous telocentric with ring-of-six at diakinesis. Feulgen preparations.

length to the arm with which it was paired. The two were therefore complementary and had no doubt arisen by complementary misdivision in a pair of homologous univalents (fig. 12). Disjunction at first anaphase was completely regular. 
This heterozygous telocentric plant, for such we may call it, provided a marker for the unbroken chromosome partner and especially for its hybridity. Wide crosses indicated by their normal ratios an equal survival of all types; and inbred families indicated by abnormal ratios an elimination of homozygotes, either telocentric or of normal mesocentric type. The principle of the hybridity optimum, demonstrated by the interchanges, was confirmed (table 1o).

TABLE Io

Inheritance of original telocentrics without reference to the rings (I45 seedlings) (see also table 12)

\begin{tabular}{|c|c|c|c|c|}
\hline & Family & Cross & $\odot \bigodot$ & Total \\
\hline Russian & Val'7 selfed & $\Theta s$ & 23 & 5 \\
\hline $\begin{array}{c}\text { Russian } \\
\times \\
\text { Western }(R)\end{array}$ & 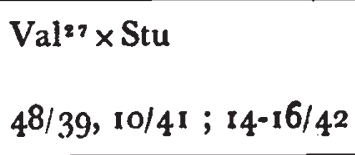 & $\begin{array}{l}\odot \times \odot(R) \\
\odot \times \circlearrowright(R)\end{array}$ & $\begin{array}{ll}10 & 5 \\
14 & 16-\end{array}$ & 45 \\
\hline $\begin{array}{c}\text { Russian } \\
\times \\
\text { Russian }\end{array}$ & $\begin{array}{l}17-23 / 42^{*} \\
17-23 / 4^{*} \\
4,5 / 4^{1} ; 8-10 / 4^{2}\end{array}$ & $\begin{array}{l}\odot \times \bigodot \\
\bigodot \times \odot \\
\odot \times \bigodot(R)\end{array}$ & $\begin{array}{cc}1 & 30 \\
2 & 20 \\
- & 3^{1}\end{array}$ & $\begin{array}{l}53 \\
31\end{array}$ \\
\hline Mixed & $7-9 / 4 I$ & $\stackrel{\leftrightarrow}{ } \times \ddot{(R)}$ & -9 & 11 \\
\hline
\end{tabular}

* In this cross between Russian stocks, and its reciprocal, the non-telocentric progeny were mostly eliminated. Evidently the telocentric heterozygotes had an advantage over the normal homozygotes (see also table I I).

Both heterozygous and homozygous telocentrics were stable. A new type of Campanula persicifolia with two pairs of telocentrics, making 18 chromosomes in all, $n=9$, was produced in the next generation in families $1 / 40$ and $3 / 40$ (fig. $4 \mathrm{C}$ ).

The telocentrics which have maintained themselves in nature are thus, as we should expect, more stable than those that have arisen in experiments in Zea and Fritillaria (Darlington, 1940a). Nevertheless they are genuinely telocentric, unlike many similar chromosomes in the Orthoptera, for they do not form chiasmata in any short arm. This is significant for they have been seen twice to form chiasmata very close to the centromere in their single long arm. Such chiasmata show, by the way, that in Campanula, as has been assumed elsewhere (Darlington, I 940 $b$ ), localisation favours chiasmata near the ends even more than it favours them far from the centromeres. Localisation is distal as opposed to proximal. It is also terminal as opposed to intercalary. And the two oppositions are balanced. 


\section{TELOCENTRICS AND INTERCHANGES}

Crosses of the telocentric stocks made between our original rings-of-ten and -twelve and derivatives from the Russian stocks brought the telocentrics into the ring (table i I).

TABLE II

Combination of telocentrics and interchanges showing the origin of chains of $5,7, I I$ and 15 chromosomes (26 seedlings)

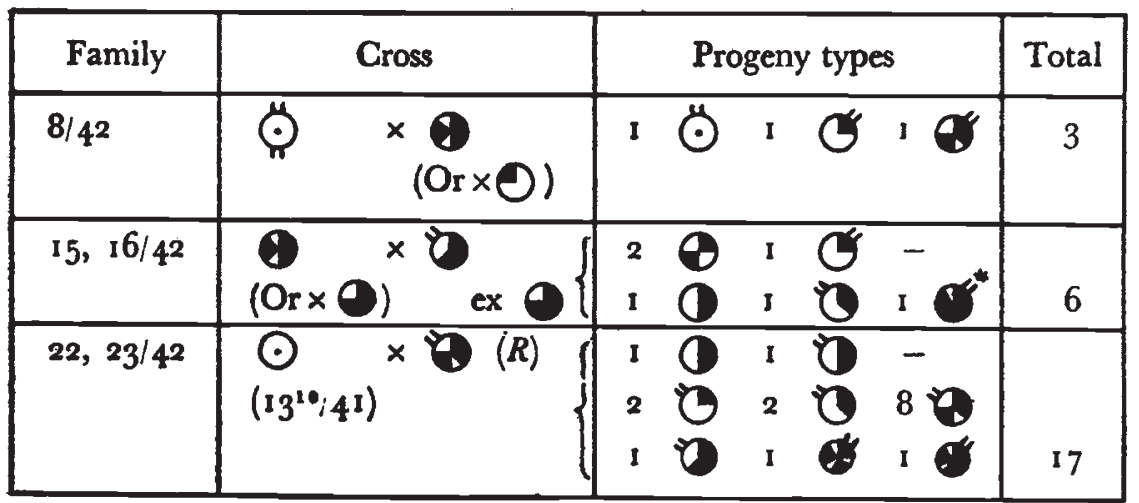

* Chain-of-fifteen.

The effect of the telocentrics is, of course, to break the ring into a chain, in one case a chain-of-fifteen chromosomes leaving out only one bivalent $\left(15^{16} / 4^{2}\right)$. The interest of these configurations is that they simulate the heterozygous conditions of sex chromosomes which are inherently self-perpetuating both in plants and animals (fig. 5). The

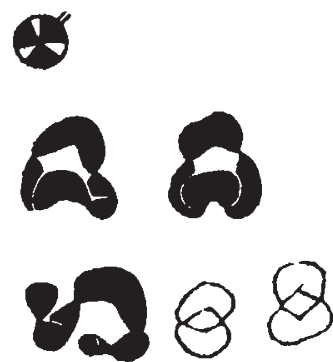

A

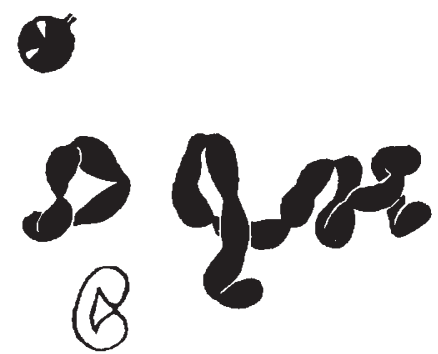

B

FIG. 5. - Telocentrics introduced into the ring.

A. In the third ring-of-four making a chain-of-five.

B. In the ring-of-ten making a chain-of-eleven.

experiment shows the simple steps by which it has long been assumed that these systems are built up (Darlington, 1932, 1937).

The analogy here is different from that with Oenothera. Species with sex chromosomes are, like Campanula, normally cross-fertilising and therefore, like Campanula-with rare and unstable exceptionsdevelop only single-interchange heterozygotes in nature. 


\section{A MONOSOMIC PLANT}

In a cross between sister heterozygous telocentrics (table I $2 a$ ) a new type of plant appeared $\left(\mathrm{I}^{12} / 4 \mathrm{O}\right)$. Externally it seemed normal apart from certain light green mutant sectors on the leaves. It had I5 chromosomes and may be represented as of the constitution $2(2)+3(4)-1$, that is to say the missing chromosome was a member of what should have been a third ring-of-four (fig. 6). Now, since

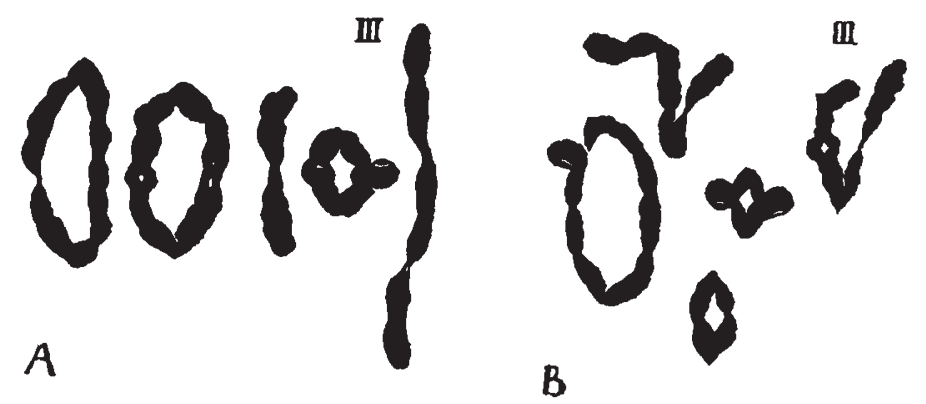

Fig. 6. - Two cells of the monosomic plant with three potential rings-of-four $\mathrm{I}^{12} / 40$.

three rings-of-four cannot be extracted from the ring-of-ten of the sole interchanged grandparent, the third ring must be due to a new interchange. The origin of a new interchange by crossing-over or an equivalent process at meiosis ( $c f$. Darlington, I93I ; fig. 27) would itself favour the three-to-one disjunction responsible for the monosomic. The two accidents must therefore be correlated and the plant derived from an $n-\mathbf{I}$ gamete.

Earlier monosomic plants had arisen by evasion of the $n-I$ generation, as with parthenogenesis in Oenothera (Stomps, 193I), with somatic mutation in many plants, or with X-rayed pollen (Stadler, I93 I) which may well have lost a broken chromosome by sister reunion of its chromatids after fertilisation.

Our monosomic resembles two more recent cases, those in Godetia (Håkansson, I945) and the grasshopper Chorthippus (Coleman, 1947) in two respects: (i) it has arisen from an $n-\mathrm{I}$ gamete; (ii) the missing chromosome is not a member of the standard complement but a new chromosome produced by interchange and probably of reduced length. It is clear that interchange followed by monosomy provides the opportunity for endless trials in nature of the viability of deficiencies. It was suggested (Darlington, 1939; fig. 19) that such interchanges might be the basis of reduction of chromosome number through loss of the new short chromosomes.

This process has now been confirmed by Håkansson's discovery (1946) of nullisomics in Godetia Whitneyi where the basic number is reduced from 7 to 6 . The precise pachytene relationships are not clear in Godetia but in Chorthippus Coleman's account enables us to reconstruct them exactly (fig. 7). They show that in fact a new 


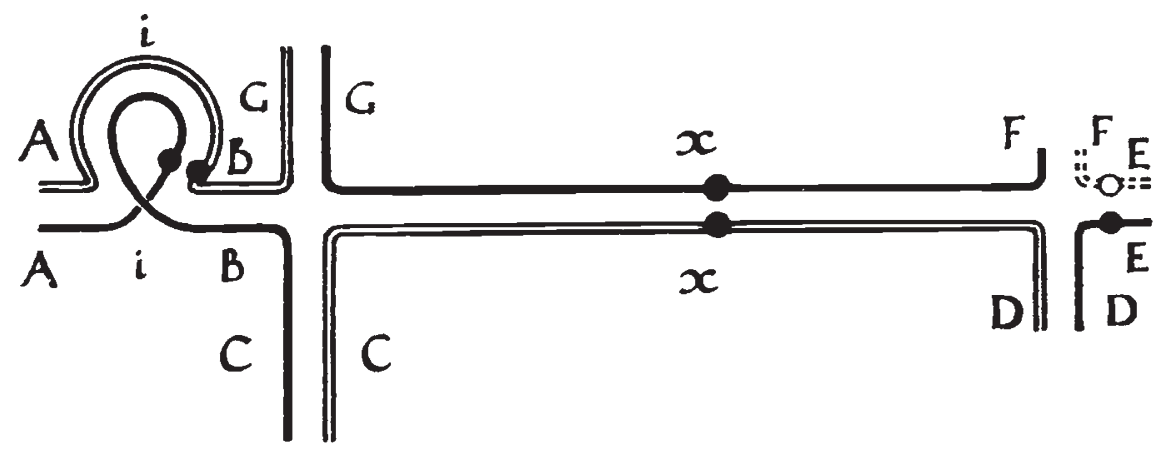

FIG. 7.-Pachytene diagram of the interchange and inversion heterozygote in Chorthitpus longicornis which has lost a new small interchanged chromosome $(F E)$. The old chromosomes are $A i B C, D E$, and $F x G$ (Coleman's 3, 7 and 1 ), the new chromosomes $A i B G, F E$ and $C x D$. The differential segment is $x$. The corresponding nullisomic, as found in Godetia, would be homozygous $A i B G+C x D$ (after Coleman).

\section{TABLE $12 a$}

History of the monosomic

Families $1 / 4^{\circ}$ and $3 / 4^{\circ}$ from sisters in $48 / 39$ crossed reciprocally. The parents are both heterozygous telocentrics with rings-of-four ex-ring-of-ten. The progeny are classified in regard to rings and telocentrics independently.

\begin{tabular}{|c|ccc|c|}
\hline interchanges & $\odot$ & $\odot$ & $\varnothing$ & Total \\
\hline$\odot$ & - & 3 & - & 3 \\
$O$ & - & 4 & 1 & 5 \\
$\Theta$ & telocentrics & 2 & 2 & 5 \\
$O$ & - & - & 1 & 1 \\
$\Theta$ & 1 $(m)$ & - & - & I \\
\hline Total & 2 & 9 & 4 & 15 \\
\hline
\end{tabular}

(m) $:{ }^{12} / 4^{\circ}$ monosomic plant with chain of three instead of two pairs,

$$
\text { i.e. } 2(4)+(3)+2(2)=15
$$

TABLE $12 b$

Sister cross, $3^{5} / 40 \times{ }_{1}^{12} / 40$ monosomic and reciprocal

\begin{tabular}{|c|c|c|c|c|c|c|c|}
\hline Family & Cross & $\odot$ & 0 & $\theta$ & 8 & 8 & Total \\
\hline $4 / 41$ & $a \times \theta-1$ & 4 & 2 & $4^{*}$ & - & 1 & n \\
\hline $5^{\prime} 4^{1}$ & Reciprocal & - & $10 \dagger$ & $1 \ddagger$ & I & - & 12 \\
\hline
\end{tabular}

* One was trisomic in some cells for one of the telocentrics, having three telocentrics $\left(4^{30} / 41\right)$.

$\dagger$ One had fragmentation of a second mesocentric chromosome to give two new telocentrics $\left(5^{\circ} / 4^{1}\right)$.

$\ddagger$ One had the two telocentrics converted into isochromosomes in some cells $\left(5^{7} / 4^{1}\right)$. 
short chromosome has been constructed-an experimental candidate for redundancy of the kind required by our evidence of the evolutionary reduction of chromosome numbers in many families of plants $(c f$. Darlington and Mather, 1949; fig. 85).

The progeny of our monosomic, however, show that it is incapable of producing effective $n-1$ gametes (table $12 b$ ). Its seedling fertility in reciprocal crosses with a sister plant with two rings-of-four was 5 per cent. or half the standard recorded for the two rings-of-four (table 8). The Campanula monosomic is therefore, like that in Chorthippus, an unsuccessful attempt to do what in Godetia has succeeded (cf. Hiorth, 1948).

\section{NEW TELOCENTRICS AND ISOCHROMOSOMES}

New interchanges are demonstrable in other crosses (table 4) but these are not the only new changes to occur.

One trisomic plant $(5 \% / 4)$ of the cross : monosomic by homozygous telocentric with two rings-of-four (table $12 b$ ) was doubly heterozygous for the telocentric condition (fig. 8A). One of the chromosomes of
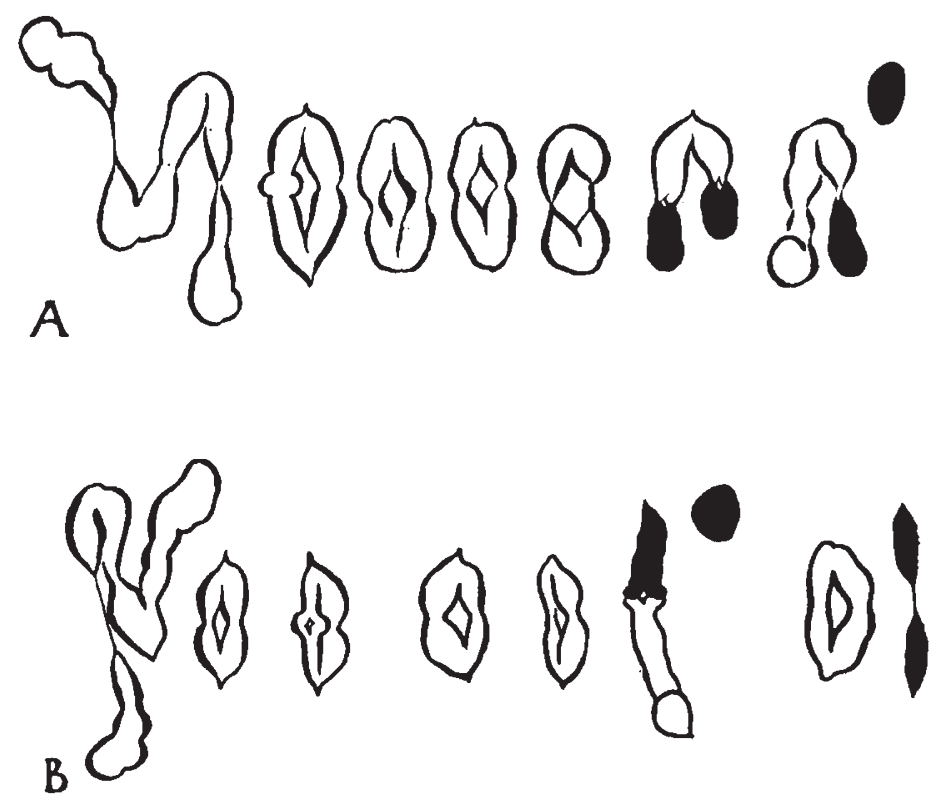

FIG. 8.-Two cells of $5^{9 / 4 \mathrm{I}}$ heterozygous for two pairs of telocentrics (in black) one of which is supernumerary, i.e. trisomic.

A. One of the trisomic telocentrics is unpaired.

B. One of the disomic telocentrics is unpaired; two homologous supernumerary telocentrics are paired with one another, i.e. they are tetrasomic.

the trisomic association had broken up to give two new telocentrics. This would happen presumably as a result of failure of pairing in the corresponding bivalent at meiosis in either parent followed by complementary misdivision of the two univalents (fig. 12). 
The normal homologue of the broken chromosome showed another variation. It was reduplicated in some cells which were therefore trisomic for this chromosome and showed the expected variable configurations, both, one, or neither of the telocentrics pairing with the unbroken chromosome. In addition the telocentrics varied in frequency from cell to cell. Their centromeres, as was to be expected with new telocentrics, were not of the standard activity. In consequence two homologous telocentrics were sometimes found in the same cell and paired (fig. 8B).

As might be foreseen from their erratic behaviour, the new telocentrics seem to have been lost in the bulk of the progeny of
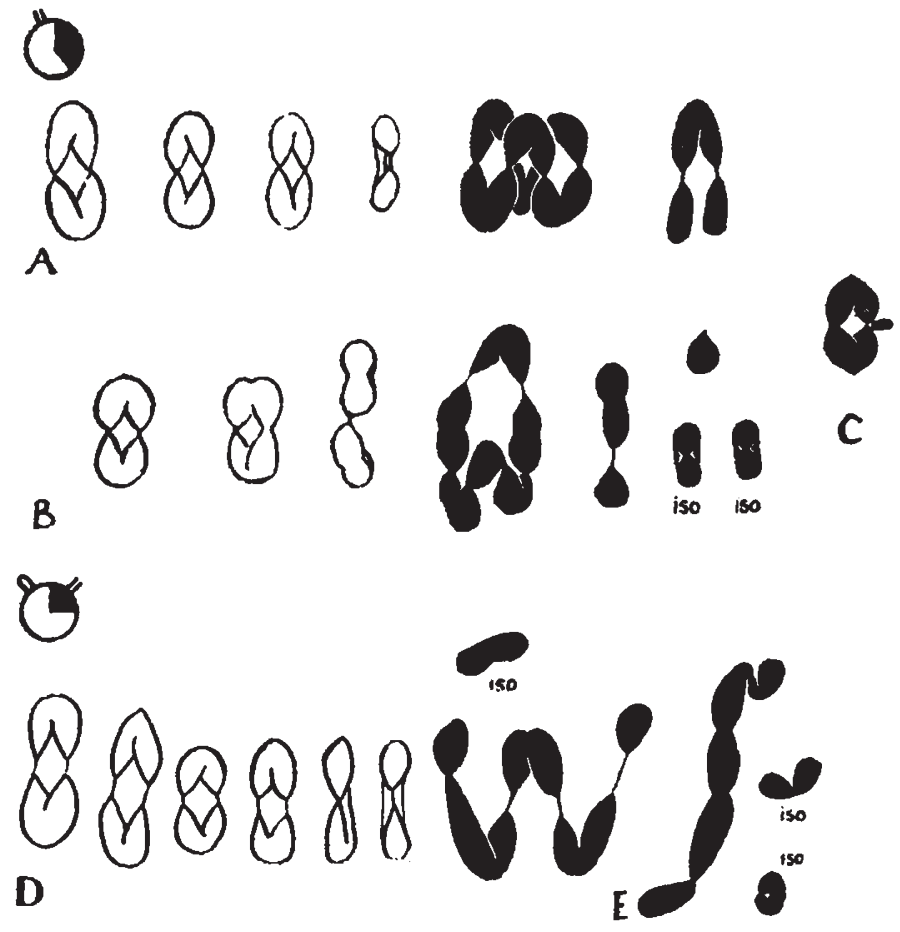

FiG. 9. - Heterozygous telocentric with ring-of-six $\left(20^{1 / 42}\right)$.

A. Cell without isochromosomes.

B. Cell with two isochromosomes and stickiness of chromosomes; one telocentric unpaired.

C. Bivalent to which the new minute fragment which arose in families $I$ and $2 / 42$ is attachęd by a triple chiasma $\left(2^{10} / 45\right)$.

$\mathrm{D}$ and $\mathrm{E}$. Telocentrics in a chain-of-five $(\mathrm{I} / 42)$.

D. With one isochromosome.

E. With two isochromosomes (bivalents omitted).

this plant crossed either way with a non-basic homozygote (20 and $21 / 42$ ). Out of the 17 seedlings, I 5 were heterozygous for the old pair of telocentrics and two had no telocentrics at all (table I3). One of the 15 , however $\left(20^{1} / 4^{2}\right)$, had, in addition to the balanced complement, one or two isochromosomes, i.e. chromosomes with two identical arms (fig. 9). This unbalance led to stickiness of the 
chromosomes at meiosis. The isochromosomes had presumably arisen by secondary misdivision (due to sister reunion in the centromere) in

TABLE 13

Family histories of the unstable isochromosomes derived from the Russian telocentrics, crossed with the monosomic to give 59!4I and the stable isochromosomes derived from new telocentrics which arose along with minute fragments and tetraploidy in the $2 x / 4 x$ chimera $18 / 40$.

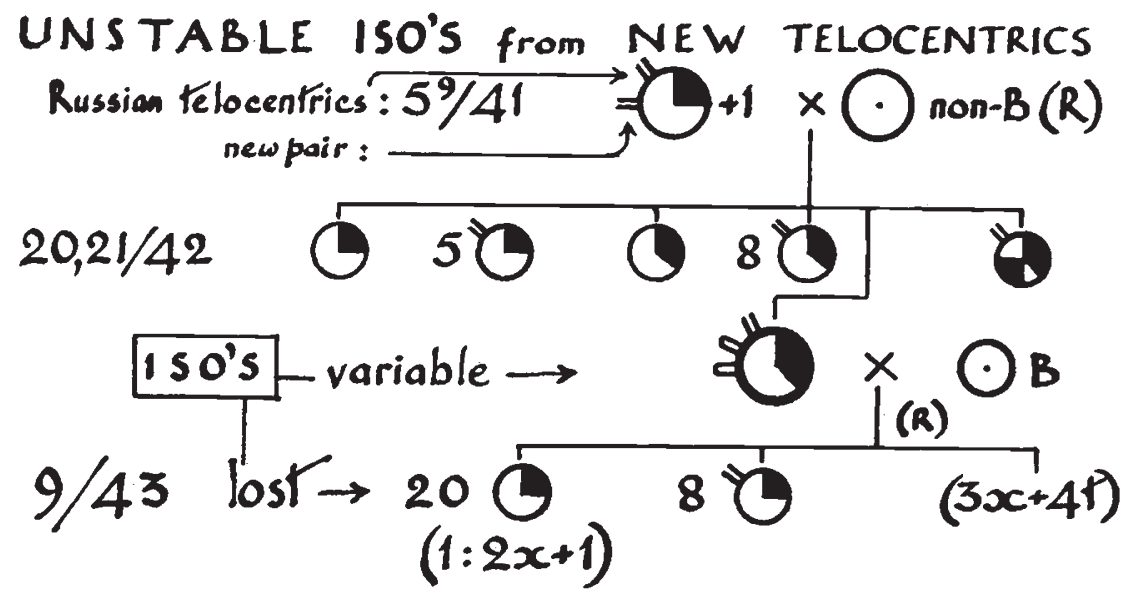

STABLE ISO'S from RUSSIAN TELOCENTRICS

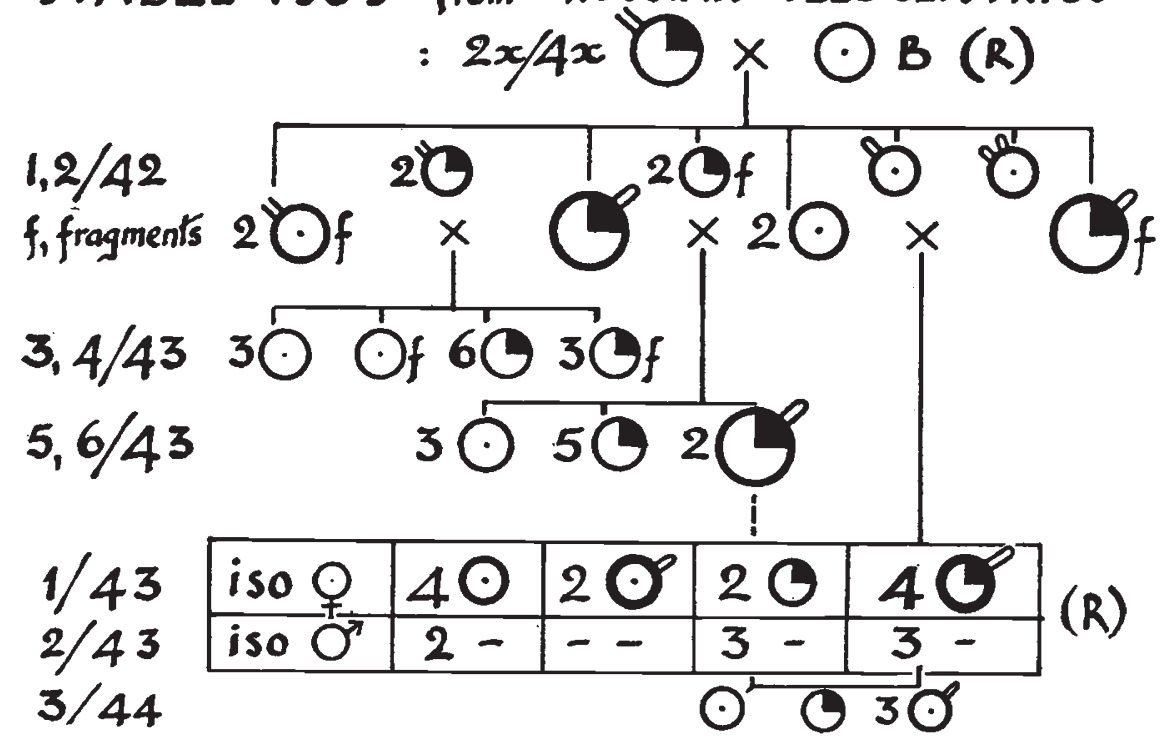

the new and unstable telocentrics. These, as we saw, suffered from the additional disability of being frequently unpaired at meiosis, a circumstance favouring misdivision, primary or secondary.

The isochromosomes varied in number. In some anthers they had been lost and a fixation of the same plant the following year 
failed to reveal them. At pre-meiotic mitoses they were evidently liable to undergo further misdivision and, having lagged, they were seen to have been cut by the cell wall.

The progeny of $20^{1} / 4^{2}$ included a trisomic and a triploid but no plant with isochromosomes. The isochromosomes in this line may therefore be described as unstable.

In a second line the situation was different (table 13 ). This line arose from a cross between a basic homozygote of the Xanthi stock and a plant of Russian descent, presumed from its crosses to be a heterozygous telocentric with a ring-of-four. This plant was scored

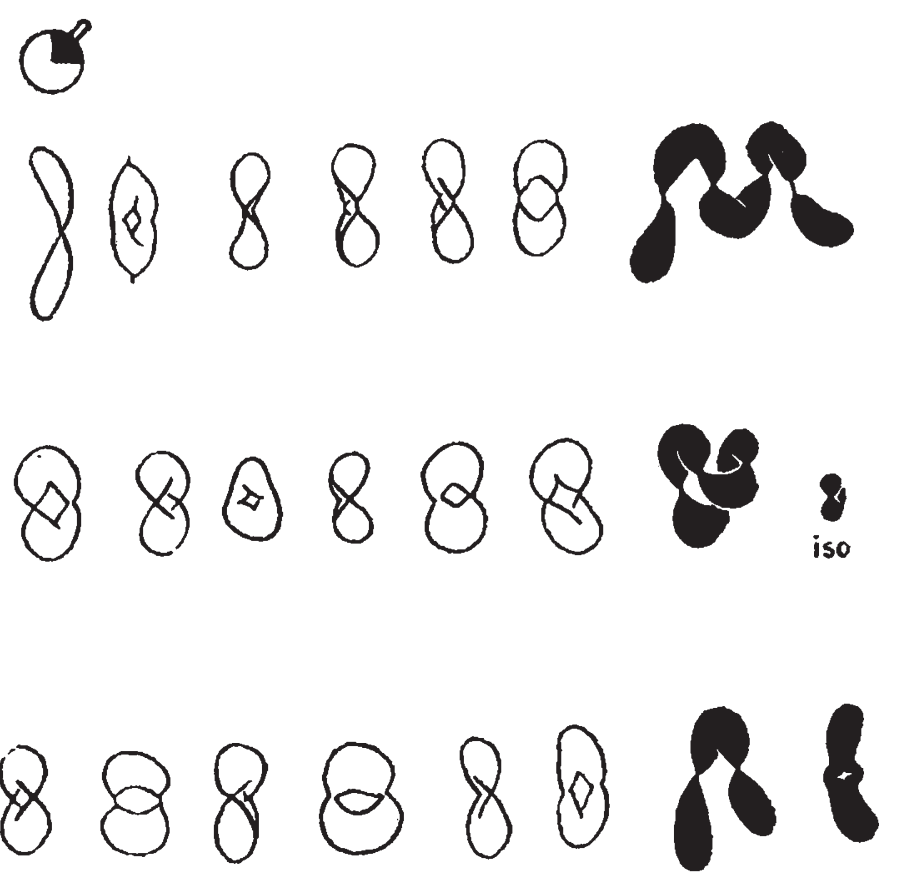

FIG. I0.-Isochromosome homologous with arms of two chromosomes in a ring-of-four and giving, therefore, a ring, or chain-of-five, or its components.

only from a tetraploid shoot and it was doubtless somatically irregular, like $5^{9} / 4^{\mathrm{I}}$ and like one of its own daughters, for in some crosses it gave no isochromosomes at all. In this cross, however, amongst I 2 plants it gave two with one isochromosome and one with two. These isochromosomes were, as in $20^{1} / 4^{2}$, supernumerary to the balanced complement. One of the three plants had derived its isochromosome through the pollen, two through the eggs ( $\mathrm{I}$ and $2 / 4^{2}$ ). In addition, two of the I 2 plants had extra centric fragments which were too small to recognise as telocentrics or isochromosomes. Such fragments may well have arisen from such lagging and cutting of isochromosomes as was seen in $20^{1} / 4^{2}$. 
One of the isochromosome plants, crossed with a plain sister reciprocally, gave progeny carrying the isochromosome, again both through the pollen and the eggs. Also, two of their sister seedlings, scored as free from isochromosomes or telocentrics $\left(2^{5}\right.$ and $\left.2^{8} / 4^{2}\right)$ when intercrossed gave two seedlings with isochromosomes $\left(6^{7}\right.$ and $6^{9} / 43$ ). One of the parents must therefore have had these chromosomes in a part of its cells. The offspring for the first time showed pairing of the isochromosome with a member of a ring. A number of the various possible configurations were found (fig. Io). But these did not include a ring-of-five.

\section{THE ORIGIN OF ISOCHROMOSOMES}

In some of the first instances isochromosomes arose early in development to give chimæras. The precise conditions of a later origin, however, have recently come to light in a family $\mathrm{I} / 48$ with 26 plants derived from $9^{3} / 43$ (table 13 ). Thirteen plants had the usual 7 bivalents and the chain-of-three of the heterozygote. Of these, ten developed isochromosomes, apparently in every anther of several flowers studied. Thus in $\mathrm{I}^{2} / 48$ (fig. I I) the following frequencies were found in single anthers :-

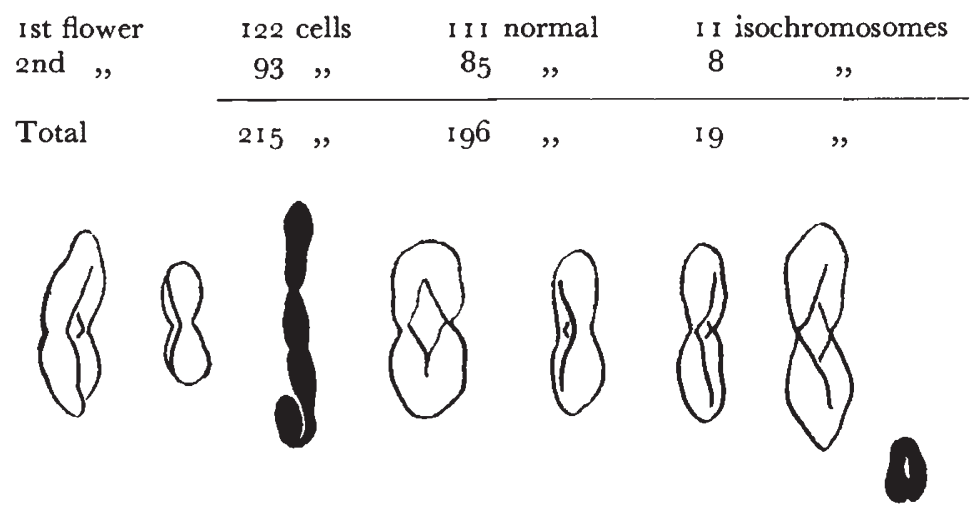

FIG. $x x$. - Meiosis in the plant $x^{2} / 4^{8}$ in which an isochromosome has arisen from one of the two telocentrics at a pre-meiotic division.

In 9 per cent. of cells one telocentric had been transformed into an isochromosome. Since two isochromosomes were never found in one cell, the one was presumably always derived from the same telocentric, one with a weaker centromere. Presumably also, cell conditions were unfavourable for spindle development in some premeiotic mitosis. The pre-meiotic stages were therefore examined in preparations of sectioned material.

In the normal development of the anthers of flowering plants the mitoses in the mother-cell precursors are synchronised. In these plants, however, synchronisation was upset (confirming the abnormality 
of cell conditions) and study was therefore more difficult. The passage of an undivided telocentric to one pole was, however, seen three times. This process should give (as previously seen in pollen grains) an isochromosome together with a telocentric in one cell and the same telocentric alone in its defective partner cell. Thus, if A. and B. are the two telocentrics and A.B the normal chromosome, mitosis takes the following course (fig. I2) :-
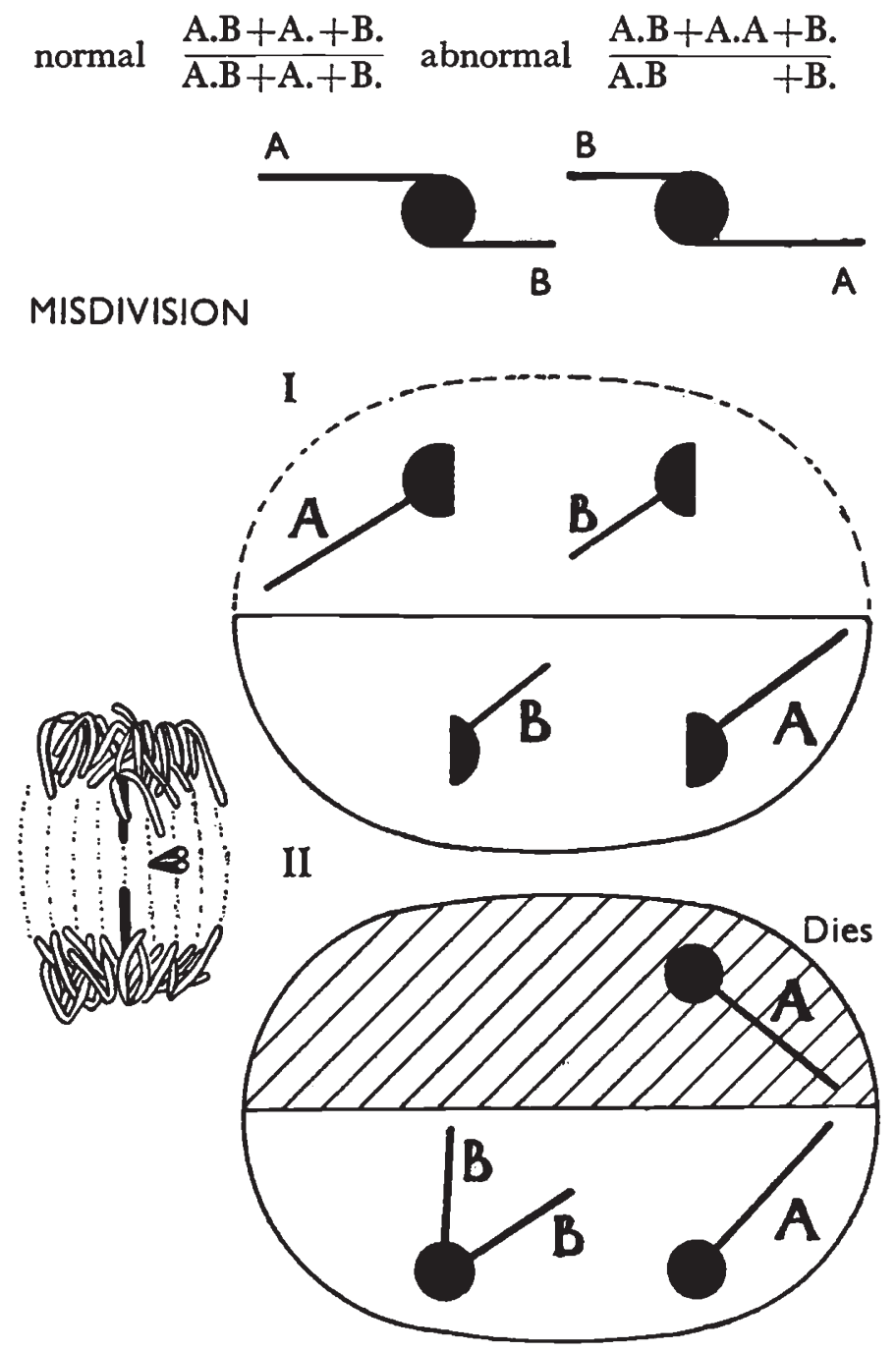

FrG. 12.-Diagram showing the origin of telocentrics by complementary misdivision and the breakdown of one of them by secondary misdivision. Pre-meiotic anaphase showing normal division of one telocentric and secondary misdivision (non-division of centromere) of the other, giving an isochromosome ( $c f$. Plate I, fig 6$) . \quad \times 3200$.

It is therefore remarkable that the corresponding 9 per cent. of defective pollen mother-cells were not found. The secondary mis- 
division of the centromere and the origin of the isochromosomes take place two or three mitoses before meiosis and in the intervening period the complementary defective cells must degenerate and disappear. This process of complementary origin and elimination seems to account for the apparent simple transformation of telocentrics into isochromosomes in so many of our plants.

At the same time it will be seen that the systematic elimination of a defective type of cell regularly arising is a notable example of the principle that natural selection must operate rigorously at the cell level if plants and animals are to attain to a uniform and healthy maturity.

In the abnormal plants studied in 1948 (although not in 1949) there was a failure of correct differentiation of the anther and other flower parts which were malformed and sometimes doubled. This error of form was no doubt the external sign of an internal upset in development of which the non-synchronisation of mitoses and the genetic change in the chromosomes were internal symptoms. The regularity in the irregularity enabled us to trace the causal sequence of what might otherwise have been an elusive and conjectural property.

\section{POLLEN-GRAIN INHERITANCE}

A Feulgen technique was developed for studying pollen-grain mitoses in 1946. The normal pollen grains in the diploid Campanula have 8 chromosomes with nearly but not quite equal arms. One of them has a wide centric constriction: the nucleolar organiser adjoins the centromere to give this effect (see appendix). The pollen grains of the plant $\mathrm{I}^{2} / 4^{8}$ with one unstable telocentric had a distribution of the eighth autosome A.B, or A. +B., as shown in table I4.

TABLE 14

Distribution of the A.B autosome in 74 pollen grains of $I^{2} / 4^{8}$

\begin{tabular}{|c|c|c|}
\hline \multicolumn{2}{|c|}{ Balanced } & Unbalanced \\
\hline +A.B. & . $3^{8}$ & $\begin{array}{l}+ \text { A.A } \\
+ \text { A.B. }+ \text { A.A } \\
+ \text { A.A. }+ \\
+ \text { A.B + B. (or A.) } \\
+ \text { B. (or A.) }\end{array}$ \\
\hline Totals & 60 & . 14 \\
\hline
\end{tabular}

Thus 19 per cent. of the pollen grains were unbalanced and most of them had the isochromosome A.A. This indicates a still higher frequency of isochromosomes in the mother-cells or, i.e. more 
than that in the mother-cell samples examined. A further point of interest is that 8 of the 74 pollen grains are defective in respect of an A. or B. arm : they are nullisomic for these half-chromosomes. Thus, although such cells are eliminated before meiosis they are not eliminated in the young pollen grain.

\section{THE FUTURE OF ISOCHROMOSOMES}

Apart from the two isochromosome lines we have the 236 seedlings of plants with stable and regularly paired telocentrics, heterozygous or homozygous. In all these no plant occurred with an isochromosome. Doubtless in these plants failure of pairing would have led to the

TABLE 15

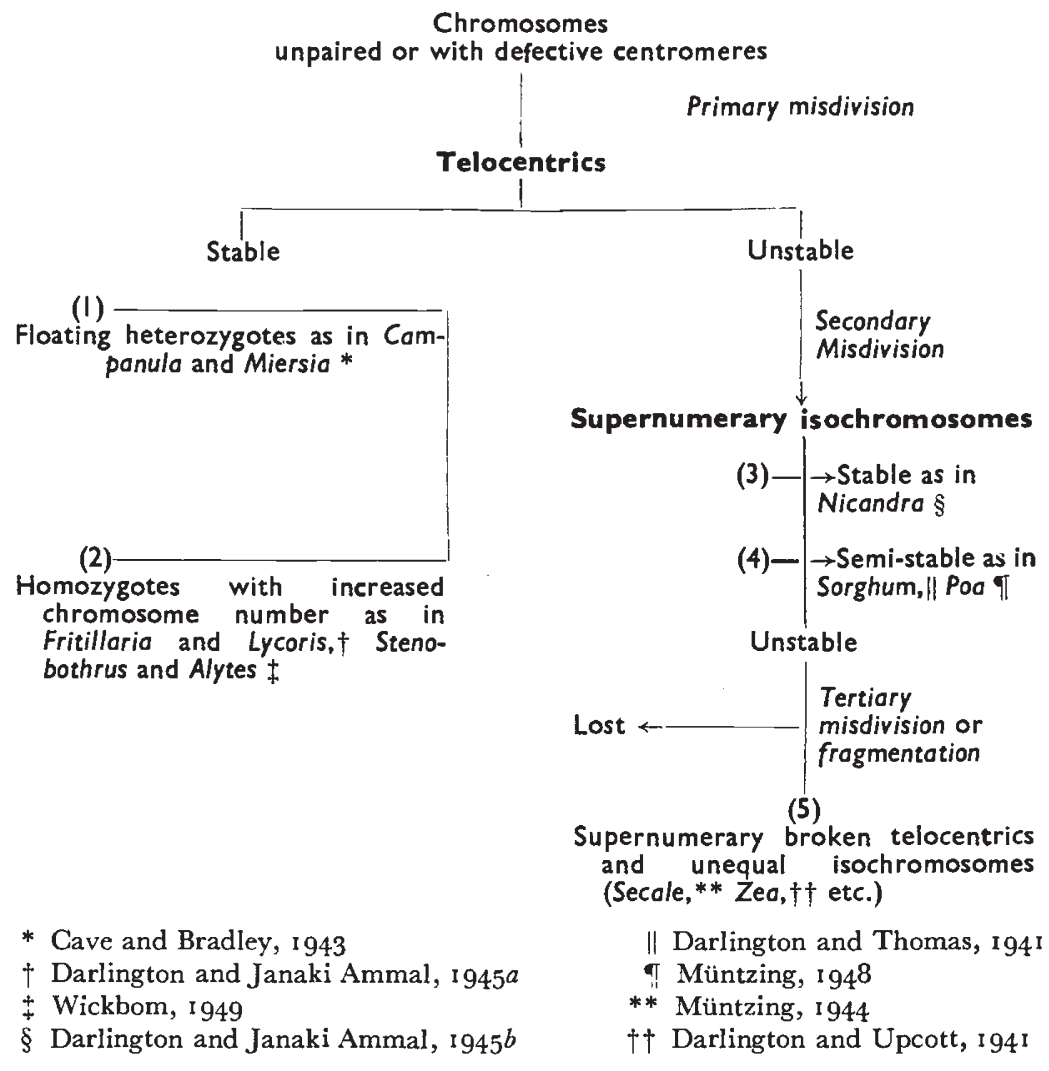

origin of isochromosomes from the telocentrics at meiosis. In its absence, however, isochromosomes can arise even at mitosis but only, as we see, where the centromere of the telocentric is untested by natural selection and unstable. For this reason they appear as supernumeraries to the ordinary complement.

Like new telocentrics isochromosomes may turn out to be stable, having a competent centromere. If unstable they will be irregularly 
distributed even at mitosis and liable to further misdivision and fragmentation. But if stable they may be transmitted by pollen and eggs and become established in the species as in Nicandra (Darlington and Janaki Ammal, 1945b). Such stable isochromosomes are probably very common, e.g. in Haworthia Browneana (Resende and Franca, 1946) and Tulipa saxatilis, $3^{x}$ (Upcott and Philp, 1939). And again both telocentrics and isochromosomes may be stable in some tissues, and not in others, giving the condition for differentiation as in Sorghum. From such chromosomes probably arise the bulk of supernumerary fragments which, as in maize and rye, betray their origin by an inadequacy of the centromere at one stage or another. Thus we may represent the historical alternatives diagrammatically as in table 15 .

\section{THE EVOLUTION OF CHROMOSOME NUMBERS}

Telocentric chromosomes seem to arise in Campanula as elsewhere by misdivision following failure of pairing at meiosis. These conditions occur in all sexual organisms, although some species and races, like our Russian stocks, are, it seems, genotypically predisposed to suffer misdivision more frequently than others. Three new origins of telocentrics in our experiments all occurred in descendants of the Russian stocks. Survival, however, will depend on other circumstances. Two complementary telocentrics must arise, as we saw, by double misdivision at the same time to give the simple "fragmentation" of a chromosome so often imagined to account for change of number without change of balance. Single misdivision will permit only of supernumerary fragments such as are widely known and such as we found in certain families. There is then the mechanical obstacle to be overcome. If the centromere is split so as to give too small a fraction to one of the telocentrics it will presumably be lost, as ours was in families 20 and $2 \mathrm{r} / 4^{2}$, unless it forms an isochromosome with twice as large a centromere. The possibilities of misdivision of the centromere will vary as between species but we must expect that in most of them only a lucky few of the new telocentrics will survive.

These conditions, difficult though they are, are no doubt fulfilled often enough to make the origin of new telocentrics an important means of increasing the basic number of chromosomes, and with it the number of linkage groups and even the balance of the nucleus as well. The differences in stability of basic numbers of chromosomes in different groups are well known and are strikingly shown by a survey of chromosome numbers in plants (Darlington and Janaki Ammal, 1945a). It would now seem that they depend to some extent on differences in the structure and stability of the centromere in the different groups.

At the same time our monosomic reveals the means of achieving the more difficult end of reducing the basic number of chromosomes. 
Its association with interchange shows the common principle at work in all such cases.

Instability of chromosome number has the common advantages and disadvantages of setting up a genetic isolation of old and new forms. In our present experiments we have used it as an additional hybridity marker. We have marker chromosomes instead of marker genes. The telocentrics, like the interchanges, show the constant action of selection in favouring the hybridity equilibrium which has been established as normal by the breeding habit of the stock concerned.

\section{CONCLUSIONS}

I. Incipient complex heterozygotes with ring-formation have been produced artificially by crossing in Campanula persicifolia.

2. They show different degrees of true-breeding in regard to ringformation according to the degree of inbreeding that is practised : the greater the inbreeding, the greater the selection for hybridity as revealed by structural hybridity. This confirms the evolutionary trend inferred from the comparison of breeding behaviour and ringformation in Oenothera.

3. The rings break down by crossing-over, which gives half-mutants with lower rings. The higher rings also give about io per cent. of trisomics whose extra chromosomes are largely eliminated in breeding even on the female side.

4. Selection for ring-size compels us to disregard selection for vigour and fertility. Vigour is steadily reduced with increasing size of the ring. The annual habit is favoured at the expense of the biennial. Fertility is also reduced in higher rings by the less regular segregation.

5. Apart from the five interchanges combined in the ring-of-twelve, four new ones have arisen in the experiments, and four other new ones have been found in natural populations, three of them in Russia.

6. In a Russian population one plant had a chromosome split by misdivision of the centromere into two telocentrics. Homozygous derivatives were bred with 9 bivalents instead of 8 . Combined with the rings in heterozygous condition they gave chains of 7, I I, I5, etc. New telocentrics arose three times.

7. Both old and new telocentrics in some genetic combinations gave isochromosomes by secondary misdivision either early or late in development. The isochromosomes were sometimes unstable, sometimes stable, being carried as supernumeraries by pollen and eggs.

8. Cells deficient for chromosome arms were formed as a result of segregation or secondary misdivision. They were lethal to pollen mother-cell precursors but not to young pollen grains.

9. A monosomic plant arose deficient for a new interchanged chromosome which had probably been produced at the parental meiosis. This shows how the basic number of chromosomes can be reduced just as the telocentrics show how it can be increased. 


\section{SUMMARY}

Experiments with ring-formation in Campanula persicifolia and the origin of interchanges, monosomics, telocentrics and isochromosomes reveal the principles by which the chromosomes are organised and their basic numbers changed up and down. Structurally hybrid types are used as a means of identifying the opposed processes of selection at work with opposed habits of inbreeding and outbreeding. They confirm our knowledge of the conservative nature of the breeding system. High rings are not genetically advantageous enough for survival in an outbreeding species. Their development is favoured by a transition to inbreeding such as is assumed to have occurred in Oenothera.

\section{APPENDIX \\ COMPOUND CONSTRICTIONS}

\section{F. LA COUR}

We find in Campanula persicifolia a chromosome pair differing from the remainder of the complement at mitosis in the root tip and in the pollen grain. They have extremely wide centric constrictions. As a rule, indeed, the arms are so wide apart as to appear completely separated. They further diverge in the behaviour of their arms. At metaphase, the chromatids in one arm are widely separated and, as a rule, lie flat in the plate. In the other arm, the chromatids are usually found close together and lying in an axial plane. In other words, the arms are relatively rotated through a right-angle on opposite sides of the centromere (figs. I3, 14 ; plate II, fig. 4).

We first supposed that these chromosomes might be associated with the origin of telocentrics in certain strains. This, howeve $i$; is not the case for they are present equally in plants with telocentrics and isochromosomes. Moreover, their behaviour at anaphase is strictly normal ; misdivision of their centromeres has not been seen and neither do they separate before the other chromosomes.

The singular behaviour of the arms would seem to be due to an eccentric position of the centromere. Presumably it is nearer the arm in which the chromatids remain together. This, together with the wide separation of the arms, implies that the unspiralised thread is lengthened in some way on one side of the centromere.

Two possibilities come to mind as to providing an explanation for this condition : (a) unspiralised heterochromatin at one side of the centromere or $(b)$ a close proximity of the nucleolar organiser. 
Heterochromatin is not perceptible in the resting nuclei in this species and we cannot therefore reach any conclusion as to its position on

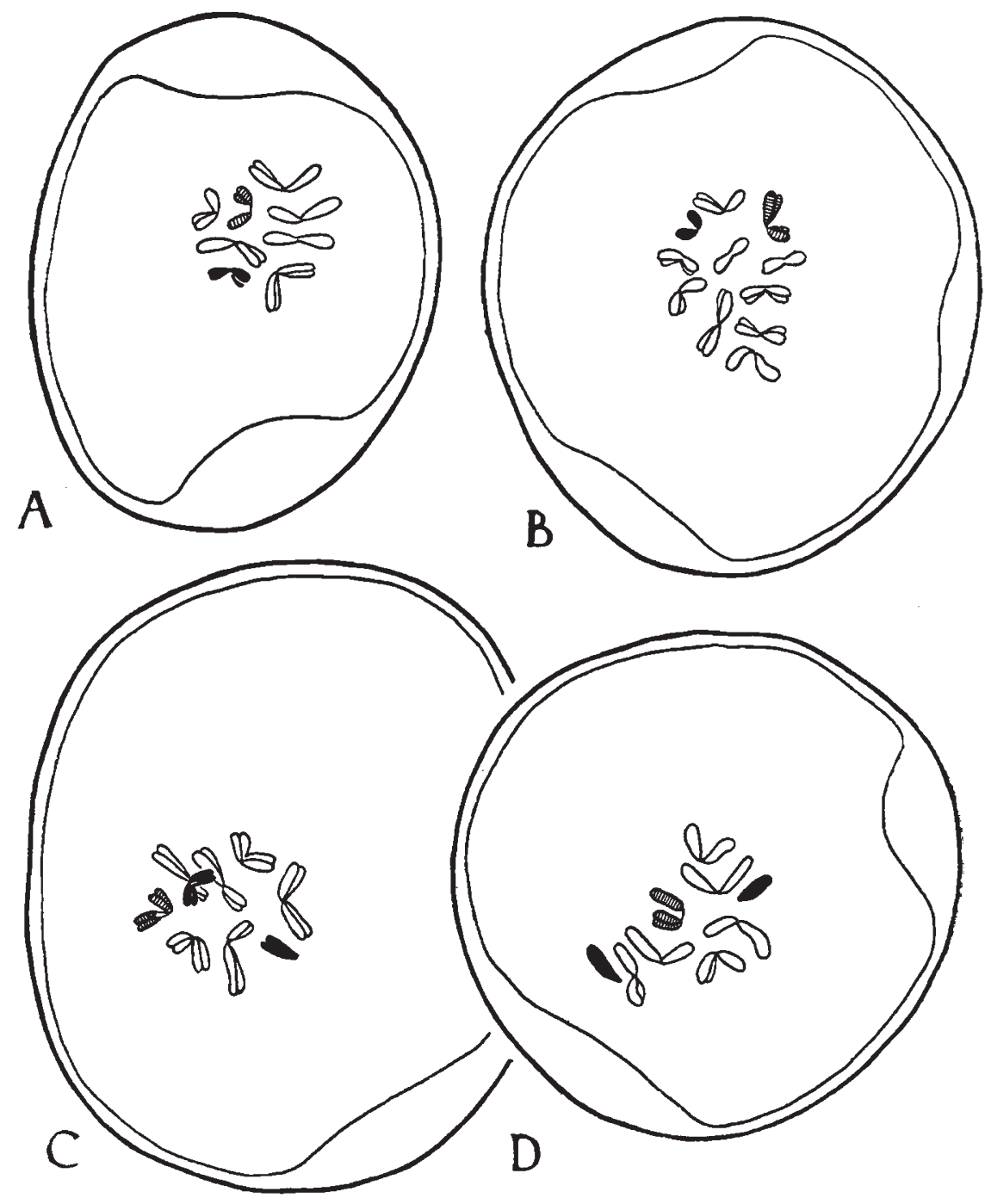

FIG. 13.-Four pollen-grain mitoses, showing the nucleolar chromosome (with wide centric constriction) stippled, and telocentrics and isochromosomes black.

A. Defective nucleus $7+i$ and B. $10+i$, both from $2^{5} / 43$.

C. Isochromosome newly arisen from telocentric in the unstable plant $\mathrm{I}^{2} / 4^{8}$ of which $\mathrm{D}$. is a normal pollen grain. $\times 1200$.

the chromosomes. The pollen-grain mitosis, however, where the prophases are very favourable for study, provides the answer to the problem. 
At metaphase a single chromosome shows the wide centric constriction and singular behaviour in the chromatids. The prophases

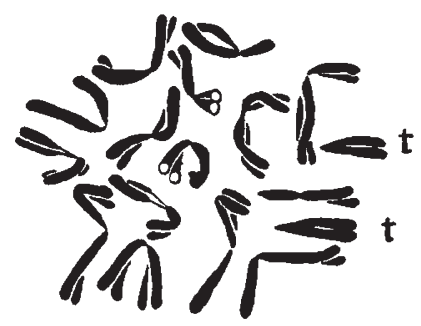

A

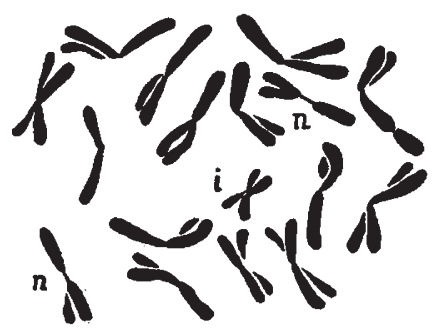

B

Frg. 14.-Root-tip mitoses, showing the wide constriction due to the combined centromere and nucleolar organiser $(n)$.

A. Unstable plant $I^{2} / 48$ with two telocentrics $(t)$.

B. Plant $2^{5} / 43$ with an isochromosome $(i) . \quad \times 3400$.

show this chromosome attached to the nucleolus, the two arms lying freely extended : the position of the organiser obviously adjoins the centromere (fig. I5).

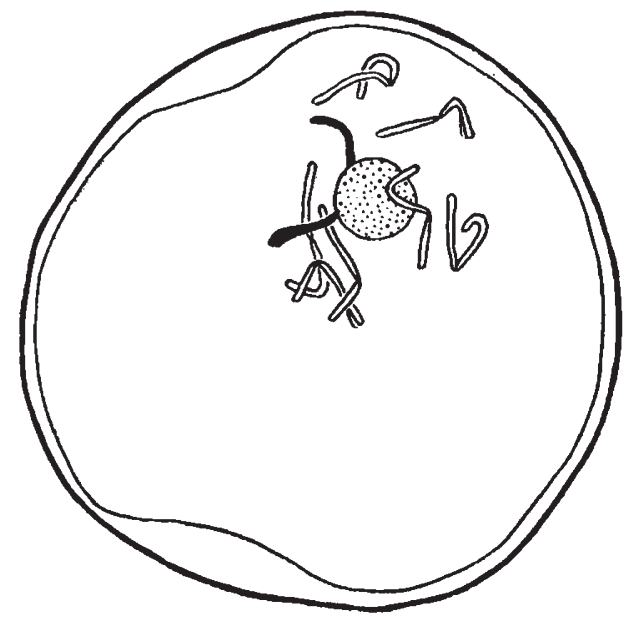

FIG. 15.-Late prophase of pollen-grain mitosis in a basic plant showing the median attachment of one chromosome to the nucleolus, the cause of the wide, compound, constriction. $\times 1200$.

A remarkably similar situation seems to occur in Poa alpina. Müntzing (1948) in this species, has observed a chromosome pair with accentuated centric constrictions and he concludes that they are the nucleolar chromosomes. He describes them as having a short arm, more intensely staining and broader than the long arm, and he infers that this arm is wholly heterochromatic. The apparent dissimilarity in the broadness of the arms may, however, be due, as in Campanula, to a difference in rotation of the arms on the two sides of the centromere. The distinction is perhaps less noticeable 
in Poa, for it is only in one of Müntzing's four illustrations (fig. 25) that the chromatids appear separated.

In Pisum we find what appears to be a more direct association of centromeres and nucleoli both in pollen and in root-tip mitoses. It is a unique situation in which all the chromosomes take part, each centromere region giving rise to a nucleolus at telophase (Håkansson and Levan, 1942). This behaviour, however (which I have confirmed), does not lead to any apparent widening of the centric constriction. We must assume therefore, that in this case, the nucleoli are organised direct from the centromeres.

There are of course other examples where, for reasons unknown, the centric constrictions appear accentuated, e.g. in Aconitum (Darlington, 1937) and in some species of Crocus (Mather, 1932). In Aconitum it is apparent in all the chromosomes of the complement while in Crocus it is usually most obvious in chromosomes associated with nucleoli formed close to the centromere. In these cases, however, we see a secondary constriction and we cannot suppose that it leads to an accentuation of the primary constriction. It may be, of course, that in these and some other cases, the wide constrictions are due to heterochromatin.

In Fritillaria lusitanica heterochromatin occurs on both sides of the centromere in most chromosomes of the set (Botelho and Mendes, 1946) and I find the same condition in another Iberian species $F$., pyrenaica. Like Paris japonica, but unlike $F$. pudica and Trillium species (Darlington and La Cour, I940, I94I), these show their heterochromatin at metaphase without any low temperature treatment. A cleaner cut distinction between heterochromatin and euchromatin, in regard to nucleic acid concentration, is, however, obtained when the plants are subjected to cold.

It may be that the heterochromatin in $F$. lusitanica and $F$. pyrenaica, because of close proximity, follows closely the cyclic behaviour of the centromeres in regard to nucleic acid. It might then be rendered visible, as understained segments, at normal temperatures. In these species, however, the arms within individual chromosomes are not wide apart as in Campanula, the starved heterochromatic constrictions are of an even thickness, approximately two-thirds the diameter of the two chromatids. It may be that in Aconitum and Crocus an unspiralised condition of the heterochromatin, as in Paris japonica, gives a picture akin to that of Campanula.

\section{REFERENCES}

BOTELHO, M., AND MENDES, E. J. 1946.

Caryological studies on Fritillaria lusitanica.

Portug. Acta Biol., I, 3 10.

CATCHESIDE, D. G. 1936.

Origin, nature and breeding behaviour of Oenothera Lamarckiana trisomics.

7. Genet., 33, I-23. 
CAVE, M. S., AND BRADLEY, M. V. I 943 .

Alteration of chromosome number in Miersia chilensis.

Amer. 7. Bot., 3o, I 42-1 49 .

CLELAND, R. E. I 944 .

The problem of species in Oenothera.

Amer. Nat., 78, 5-28.

COLEMAN, L. C. I 947 .

Chromosome abnormalities in an individual of Chorthippus Longicornis (Acrididæ).

Genetics, 32, 435-447.

DARLINGTON, C. D. I 93 I.

The cytological theory of inheritance in Oenothera.

7. Genet., 24, 405-474.

DARLINGTON, c. D. I $93^{2}$, I 937.

Recent Advances in Cytology. London : Churchill.

DARLINGTON, C. D. I 939.

The Evolution of Genetic Systems. Cambridge : University Press.

DARLINGTON, C. D. I $940 a$.

The origin of isochromosomes.

7. Genet., 39, $35^{1-361 . ~}$

DARLINGTON, C. D. I $940 b$.

The prime variables of meiosis.

Biol. Rev., 15, 307-322.

DARLington, C. D., AND GAIRDNER, A. E. I937.

The variation system in Campanula persicifolia.

7. Genet., 35, 97-1 $3^{8 .}$

DARLINGTON, C. D., AND JANAKI AMMAL, E. K. $1945 a$.

Chromosome Atlas of Cultivated Plants. London: Allen \& Unwin.

DARLINGTON, c. D., AND JANAKI AMMAL, E. K. $1945 b$.

Adaptive isochromosomes in Nicandra.

Ann. Bot., 9, 267-281.

DARLiNGTON, C. D., AND LA COUR, L. F. I 940.

Nucleic acid starvation of chromosomes in Trillium.

7. Genet., 40, I85-2 I3.

DARLINGTON, G. D., AND LA GOUR, L. F. I94I.

The detection of inert genes.

7. Hered., 32, I I 5-1 2 I.

DARLINGTON, c. D., AND THOMAS, P. T. I94I.

Morbid mitosis and the activity of inert chromosomes in Sorghum.

P.R.S., B, 130, I27-150.

DARLINGTON, C. D., AND UPCOTT, M. B. I $94 \mathrm{I}$.

The activity of inert chromosomes in Zea Mays.

J. Genei., 4I, 275-296.

GAIRDNER, A. E. I 937 .

The segregation of six factors in Campanula persicifolia.

7. Genet., 35, 28 I -288. 
GAIRDNER, A. E., AND DARLINGTON, C. D. I93I.

Ring-formation in diploid and polyploid Campanula persicifolia.

Genetica, I3, II3-I 50.

HẢKANSSON, A. I945.

Zytologische studien an monosomischen typen von Godetia Whitneyi.

Hereditas, 3I, I 29-I62.

HÅKANSSON, A. 1946 .

Meiosis in hybrid nullisomics and certain other forms of Godetia Whitneyi.

Hereditas, 32, 498-513.

HÅKANSSON, A., AND LEVAN, A. 1942.

Nucleolar conditions in Pisum.

Hereditas, 28, 436-440.

HIORTH, G. I 948.

Zur genetik der monosomen von Godetia Whitneyi.

Z.I.A.V., 82, 230-275.

MATHER, K. I 942 .

The balance of polygenic combinations.

7. Genet., 43, 309-336.

MÜNTZING, A. I 944 .

Cytological studies of extra fragment chromosomes in rye. I. Iso-fragments produced by misdivision.

Hereditas, 30, 23 I-248.

MÜNTZING, A. 1948.

Accessory chromosomes in Poa alpina.

Heredity, 2, 49-6I.

RESENDE, F., AND DA FRANCA, P. I 946 .

Sur l'origine de nouvelles formes.

Portug. Acta Biol., I, 289-307.

STADLER, L. J. I 93 I.

The experimental modification of heredity in crop plants $\mathrm{I}$.

Sci. Agric., II, 557-572.

STOMPS, T. J. I93I.

Weiteres über parthenogenesis bei Oenothera.

Ber. dtsch. bot. Ges., 49, 258-266.

UPCOTT, M., AND PHILP, J. I 939.

The genetic structure of Tulipa. IV. Balance, selection and fertility.

7. Genet., 38, 91-123.

Wтсквом, т. 1949 .

A new list of chromosome numbers in Anura.

Hereditas, 35, 242-245. 


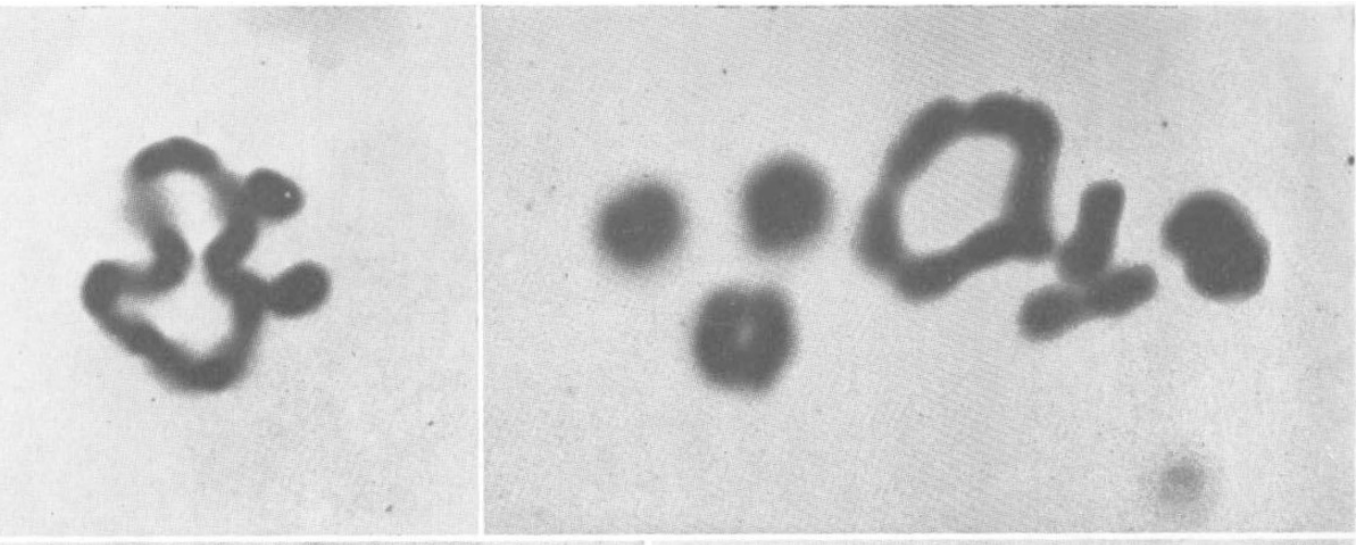

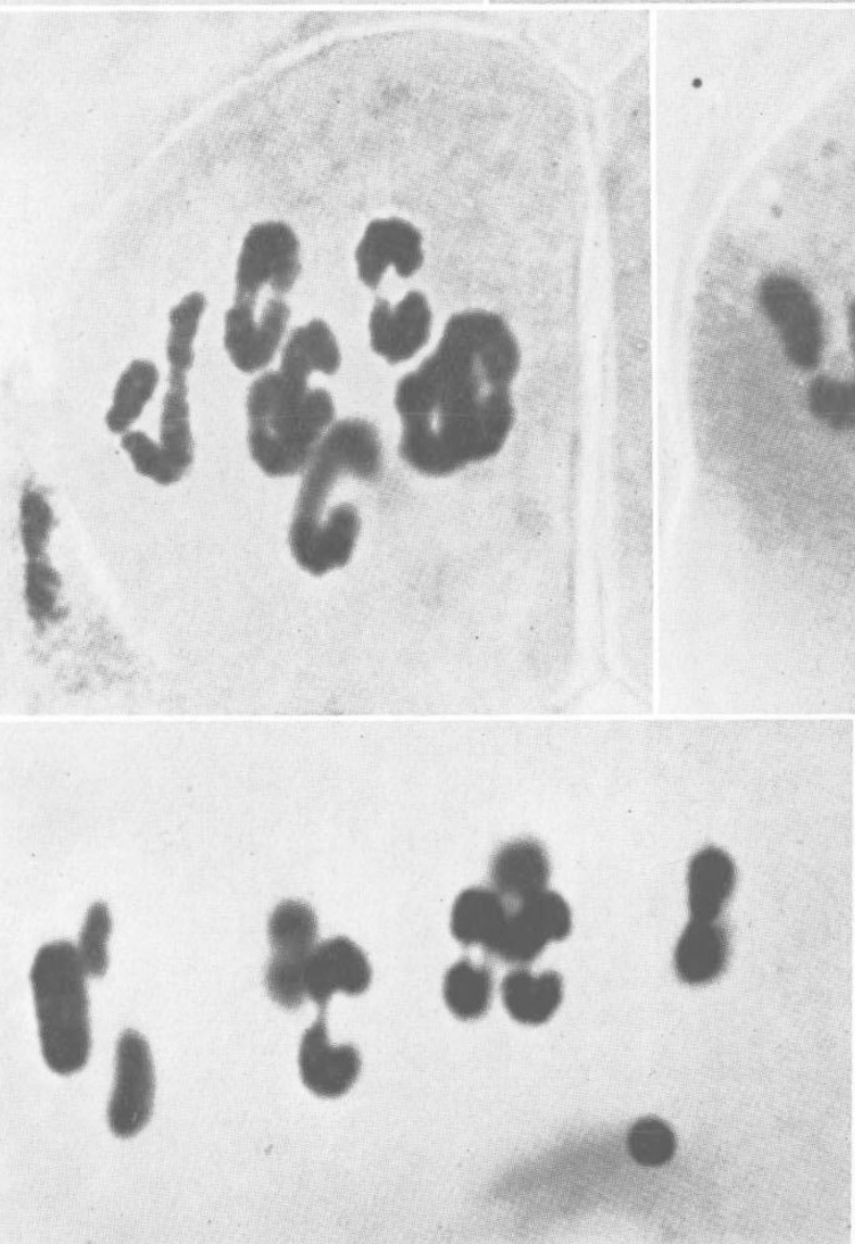

5

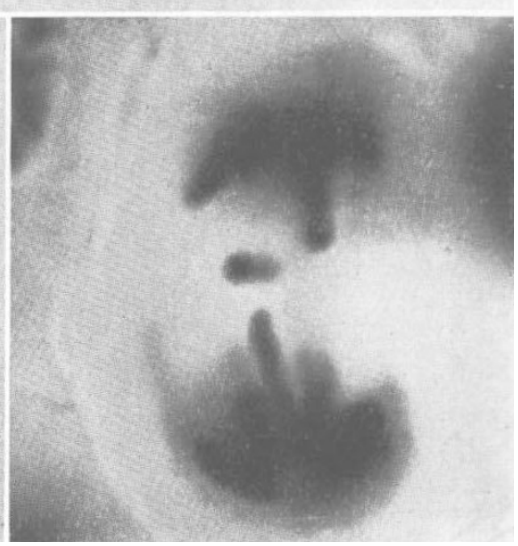

6

FIG. 1.-Ring-of-twelve and two pairs, $(12)+2(2)$, at meiosis in $68 / 3^{8} . \times 3000$.

Fig. 2.- - Homozygous telocentric and heterozygous interchange plant $1^{14} / 4^{\circ}$, with ring-ofsix and 6 bivalents : $2 n=\mathrm{I} 8 . \quad C f$. text fig. $5 . \times 3000$.

FIG. 3.-Monosomic plant $2(4)+(3)+2(2), 112 / 40,2 n=15 . \quad \times 2000$.

Figs. 4, 5, 6.-Heterozygous teloccntric plant $21 / 48$.

FIG. 4.-Chain-of-three in normal pollen mother-cell. $\times 2000$.

FIg. 5.-One of the telocentrics has been converted into an isochromosome which is unpaired having formed a chiasma with itself and is lying off the plate. The remaining telocentric is paired with its large partner. $\times 3000$.

FIG. 6.-Origin of the isochromosome from a lagging telocentric in a premeiotic mitosis. $\times 3000$. 
PlATE II.-Pollen-grain mitoses in diploid plants with telocentrics and isochromosomes. $\quad \times 2400$.
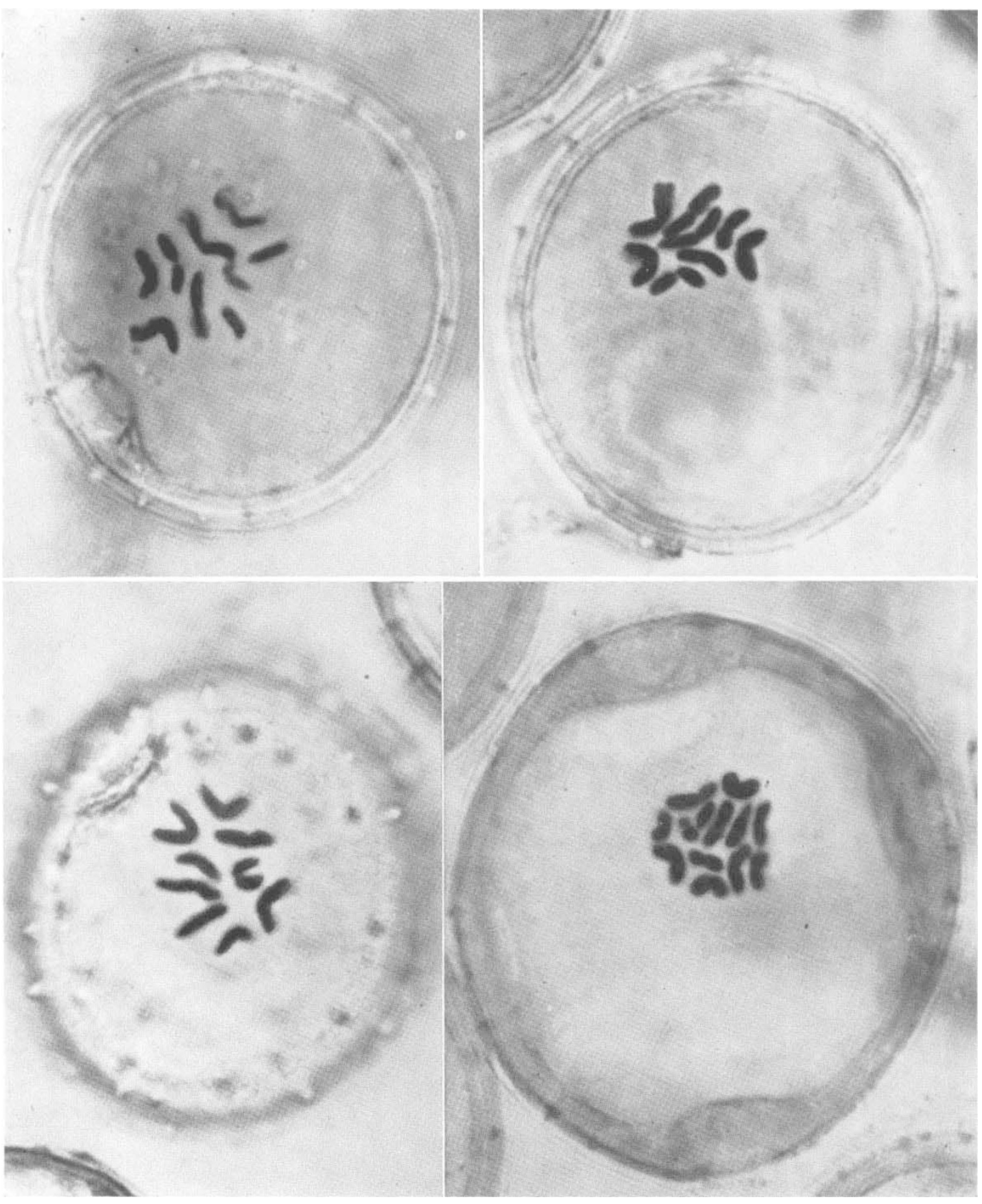

3

FIG. 1.- - Seven autosomes and 2 telocentrics at 2 and 4 o'clock; note that one has its centric end pointing outward indicating a weak centromere ( $c f$. text fig. 12).

FIG. 2.-Defective nucleus : 7 autosomes and I isochromosome (2 o'clock).

FIG. 3.-Eight autosomes and I isochromosome (3 o'clock).

FIG. 4.-Eleven autosomes and I isochromosome (10 o'clock) ; note the chromosome with the compound constriction has widely separated chromatids in the shorter arm with the nucleolar organiser and therefore seems tripartite. The three extra autosomes are due to irregular segregation in a ring. 